\title{
PROYECTO CARTEIA: PRIMEROS RESULTADOS
}

\author{
M. BENDALA GALÁN \\ L. ROLDÁN GÓMEZ \\ J. BLÁNQUEZ PÉREZ \\ S. MARTÍNEZ LILLO \\ Universidad Autónoma de Madrid
}

\section{Resumen}

En el presente artículo presentamos los primeros resultados del Proyecto de Investigación "Estudio histórico arqueológico de la ciudad púnico romana de Carteia" desarroliados durante las campañas de 1994 y 1995. En él se aborda, de forma general, el desarrollo histórico y urbanístico de la ciudad desde sus primeras etapas históricas hasta la Edad Media profundizando en el estudio del desarrollo urbanístico, de su arquitectura y de sus fases constructivas, así como del conjunto de sus materiales arqueológicos.

Las actuaciones de estas dos primeras campañas se han centrado en tres sectores del yacimiento que corresponden a tres problemas arqueológicos distintos: el estudio de la secuencia estratigráfica desde los primeros niveles de habitación de la ciudad púnica intrapuesta al foro; el análisis de la estructura del complejo monumental del templo y, por último, el estudio del período medieval.

\section{Summary}

This paper presents the results of the research project: Study of the Archaeological Roman punic city of Carteia- obtained during 1994 and 1995. This project is concetrated in a general development of the site from its first historical dates until the Middle Age going into the analysis of its urbanistic sequence, its architecture and constructive fases and its archeological materials.

The actuations of this two first years have been centered on three differents sectors that corresponded to three archaeological problems: the study of the chronological secuences from the first levels in the zone of the foro; the monumental complex of the templo, and last, the medieval period.

\section{INTRODUCCIÓN}

La ciudad de Carteia ha sido incorporada, desde hace siglos, a la literatura erudita y científica. Aunque despoblada desde la tardía Antigüedad, su importancia quedó bien reflejada en los textos antiguos, y la continua visión de sus ruinas, unido a la identificación con Tartessos sugerida por algunos autores antiguos, animaron pronto la especulación erudita desde el Renacimiento e, incluso, las primeras excavaciones arqueológicas a mediados de nuestro siglo. 

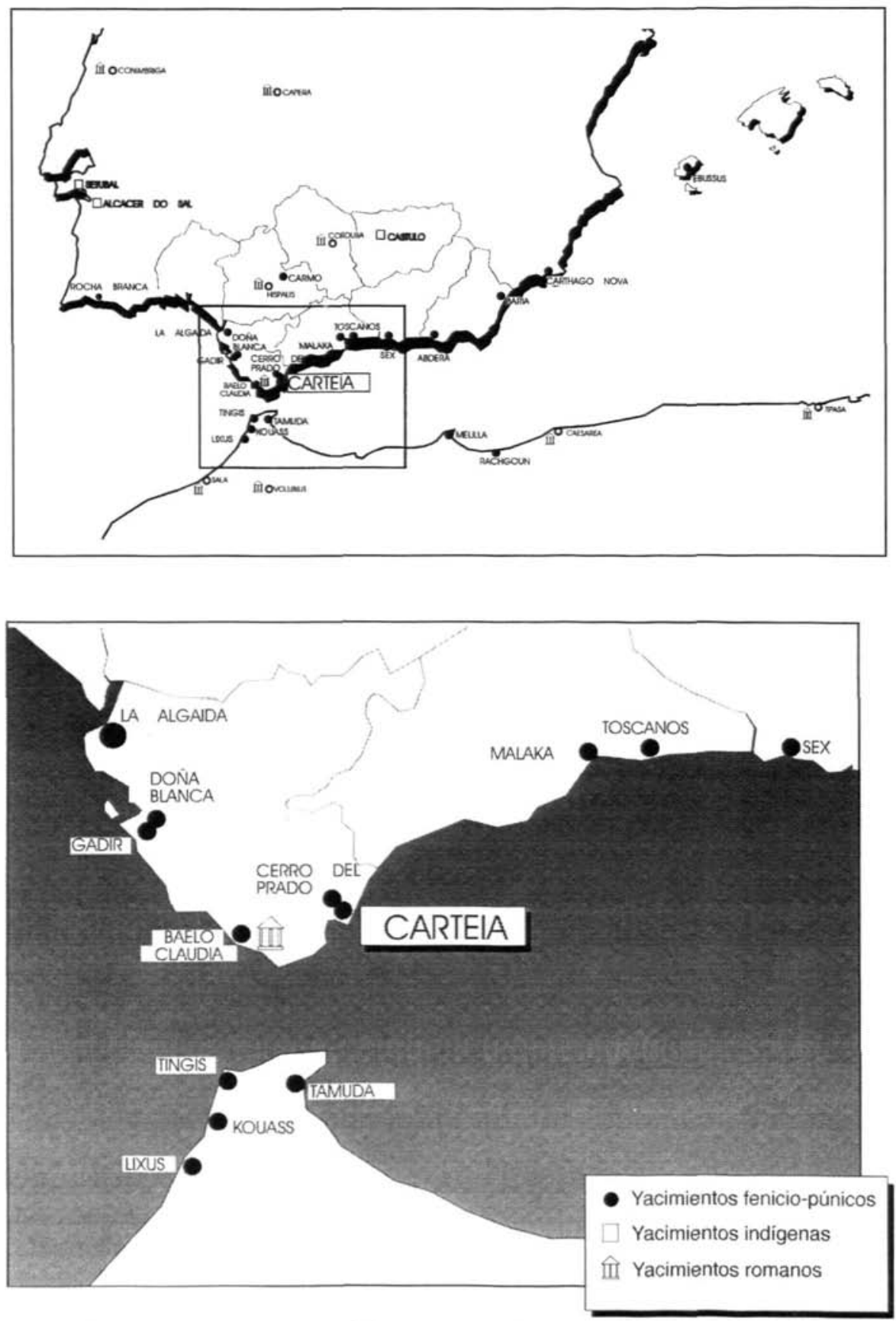

Figura 1. Uthicación general de la ciudad de Carteia en el marco del Mediterráneo Occidental y detalle 


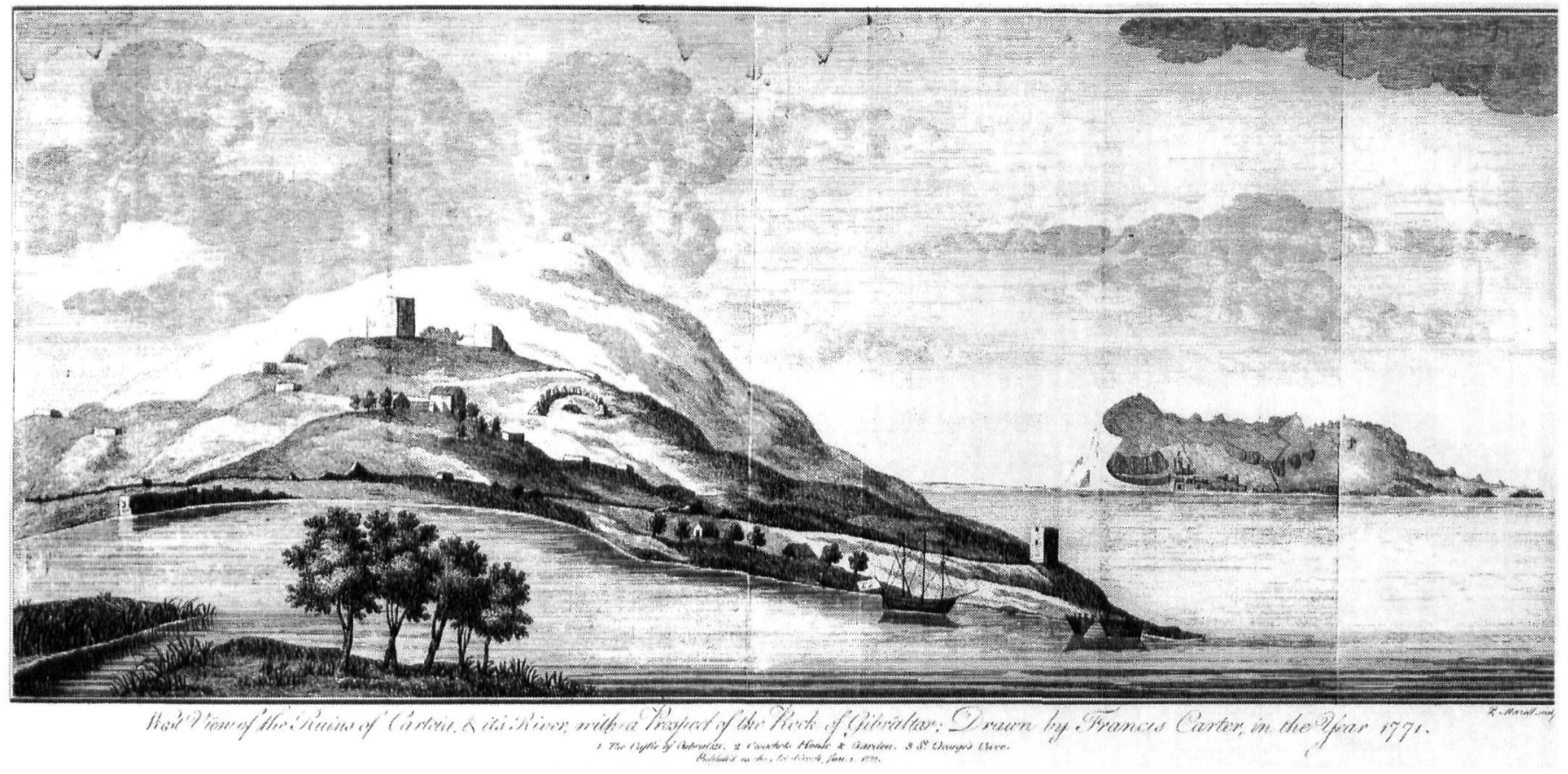

Figura 2. Vista general de la bahía de Algeciras con las ruinas de Carteia, según Carter (1777) 
Situada al fondo de la bahía de Algeciras (fig. 1), hoy término municipal de San Roque (Cádiz), la ciudad de Carteia quedó al margen de los posteriores, pero más activos, núcleos de población desarrollados en sus cercanías, como Algeciras y Tarifa. Y convertida ya en un despoblado quedaría andando el tiempo incorporada a las tierras del Cortijo de El Rocadillo, levantado en el siglo XVIII sobre la ruina de sus antiguas construcciones (lám. 1). En efecto, la parte alta del foro y los restos del templo que lo presidía servirían de base para su edificación, que ha permanecido así hasta su demolición con motivo de las excavaciones de los años 60 . No obstante, la memoria de la antigua ciudad de Carteia nunca llegó a perderse y, desde el siglo xVI, diversos autores se referirán a los vestigios arquitectónicos de algunas de sus construcciones más significativas, entre ellas el acueducto, las termas, o el teatro. Ya a comienzos del siglo XVII Hernández del Portillo llegó a identificar la Carteia romana con las ruinas del citado Cortijo de San Roque (Hernández del Portillo, 1994). Con posterioridad, Madoz (1849), Ceán Bermúdez (1832), Romero de Torres $(1909,1934)$ y Pemán (1942) volverán a referirse a la ciudad, sin olvidar las descripciones de los ingleses J. Conduit, en el s. XVII, y Carter un siglo después (fig. 2), que aportaron interesantes datos sobre las construcciones todavía visibles $-\mathrm{y}$ aún sin excavar- del yacimiento.

Los primeros trabajos arqueológicos fueron llevados a cabo en los años cincuenta y sesenta de nuestro siglo por Julio Martínez Santa-Olalla, animado por el prestigio histórico de la ciudad y, cómo no, por la teórica identificación con Tartessos siguiendo el parecer de autores antiguos de la talla de Estrabon, Plinio o Mela. Por otra parte, Estrabón $(3,1,7)$ recoge la opinión de Timóstenes de que era llamada Herákleia, lo que permitía ponerla en relación con el culto a Herakles, el Melkart fenicio venerado en el célebre santuario de Gadir que fue incorporado luego al panteón romano con la denominación específica de Hercules Gaditanus.

Las excavaciones de Santa-Olalla, efectuadas en la muralla, el teatro y la zona suroeste de las termas, le permitieron rechazar la identificación de la ciudad de Carteia con Tartessos, y definirla mejor como un asentamiento de gran antigüedad, originalmente púnico, según se contiene en la escasa documentación conservada de sus trabajos (notas de prensa y algunos manuscritos: Castelo et alii,1995, 103-114). Los años sesenta marcaron después acusadamente la historia reciente de Carteia al acometerse en toda su área la realización de un ambicioso polígono industrial que dañó sensiblemente el contexto ambiental y arqueológico de la ciudad. En 1964, para preservar lo principal de ella, se encomendó a M. Pellicer una prospección que permitió delimitar el perímetro urbano e, incluso, la ubicación de las necrópolis, con la conclusión añadida, a la vista de los materiales recuperados, de que nada en la ciudad era remontable a una fecha anterior al siglo III a.C. (Pellicer et alii, 1977, 224-225). Los trabajos de Pellicer, junto con 
los llevados a cabo por Santa-Olalla, señalan el inicio del conocimiento moderno del asentamiento de Carteia (fig. 3).

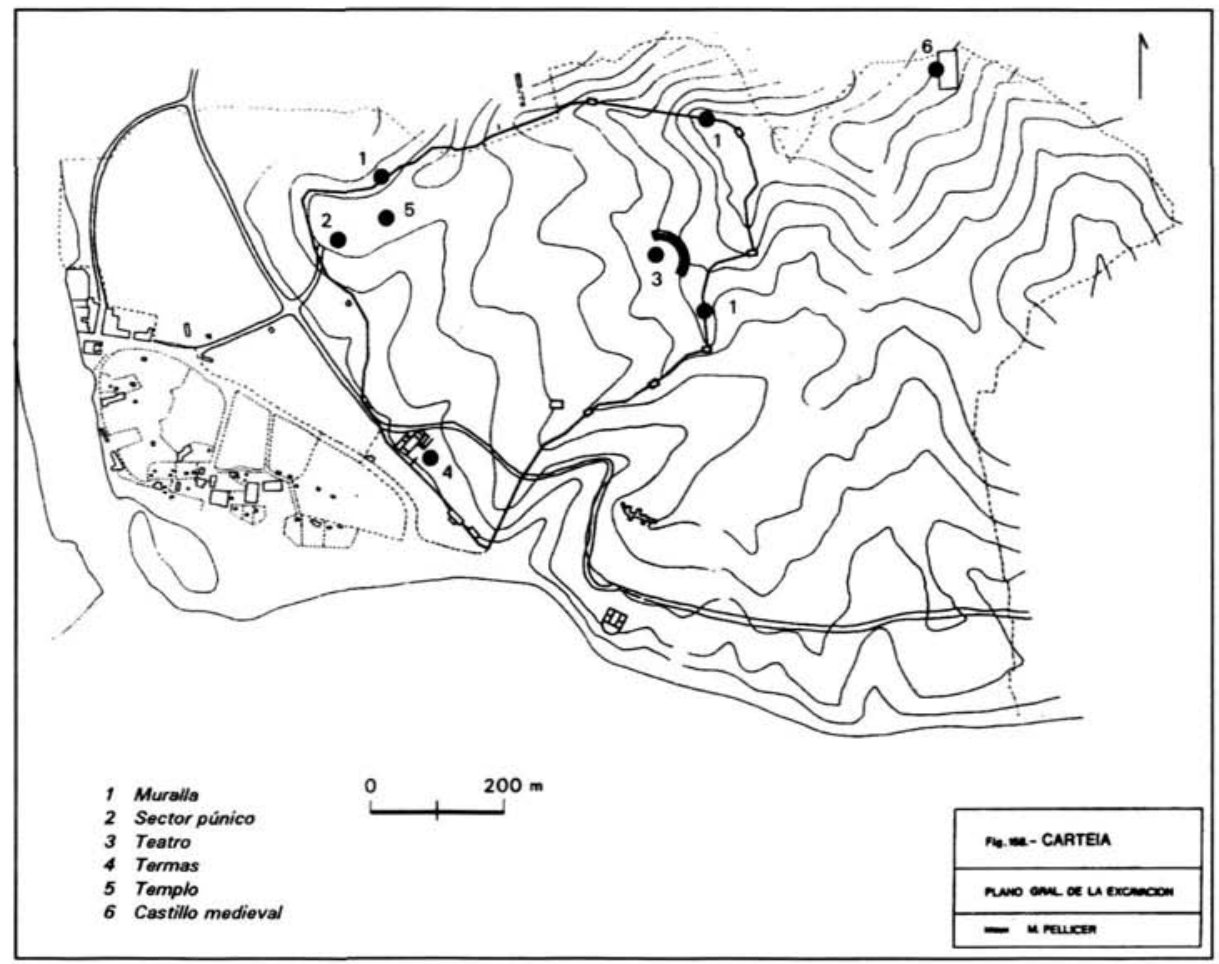

Figura 3. Plano esquemático de Carteia (según M. Pellicer), con el emplazamiento de las principales estructuras excavadas. 1) Foro; 2) Termas; 3) Villae; 4) Macellum; 5) Teatro; 6) Recinto fortificado

Un año después, en 1965, comenzaron una serie de campañas arqueológicas patrocinadas por la Bryant Fundation y dirigidas por D. Woods, F.Collantes de Terán y C. Fernández-Chicarro, muy alentadas, entre otros motivos, por la identificación legendaria de Carteia con Tartessos, el sempiterno tema de moda en la Arqueología y la Historia Antigua españolas. Durante cinco años excavaron en diferentes edificios y espacios de la ciudad (lám. 1) con la constatación, en algunos de los mismos, de la existencia de niveles constructivos superpuestos, que, desde época ibérica, alcanzaban las etapas romanas, republicana e imperial (Woods et alii, 1967; Woods, 1969).

Entre 1971 y 1985 hay que marcar una nueva etapa de excavaciones sistemáticas, en esta ocasión dirigidas por F. Presedo, realizadas con el objetivo de conocer mejor la zona del foro, en particular el edificio del templo, las termas y, en general, enriquecer cuanto fuera posible la información arqueológica que permitiera recuperar la historia antigua de la ciudad (Presedo,1977; Presedo et alii,1982; Presedo y Caballos,1988). Parale- 
lamente, se realizaron estudios centrados en otras manifestaciones culturales tales como la sistematización y valoración de sus emisiones monetales (Chaves, 1979).

A finales de los ochenta se realizaron en el yacimiento nuevas investigaciones sobre la arquitectura y la urbanística de la ciudad. Se encuadraban dentro de un ambicioso proyecto de estudio de la arquitectura hispanorromana desde el punto de vista tecnológico (Bendala, 1992), que estaba por hacer, y que condujo, entre otros frutos, a la publicación de un libro sobre las técnicas constructivas aplicadas en Carteia (Roldán Gómez,1992). Posteriormente, tras una primera campaña de análisis de la documentación y de los materiales arqueológicos procedentes de antiguas excavaciones almacenados en el yacimiento, así como de aquellos depositados en el museo de Sevilla (Roldán Gómez, 1995a), se concibió la puesta en marcha de un ambicioso Proyecto de Investigación bajo los auspicios de la Consejería de Cultura de la Junta de Andalucía, el Estudio bistóricoarqueológico de la ciudad púnicorromana de Carteia (Roldán Gómez, 1995b, e.p.). En él se aborda, de manera integral, el proceso poblacional de Carteia, desde sus primeras etapas históricas, hasta la Edad Media. Se trataba de conocer y profundizar su implantación territorial, la evolución espacial, el desarrollo urbanístico, la caracterización de sus diversas fases constructivas, el estudio de su arquitectura y el conjunto de los materiales arqueológicos. Dirigida la investigación por los dos primeros firmantes de este artículo, cuenta, desde su inicio, con la participación de un amplio equipo de profesores de las Universidades Autónoma de Madrid y Cádiz, especialistas en los diferentes campos culturales contemplados y requeridos por el Proyecto.

\section{LOS TRABAJOS ARQUEOLÓGICOS}

Las tareas de campo han comenzado en 1994 con el estudio de los restos monumentales dispersos por diversos Museos y en el propio yacimiento. Paralelamente, se ha trabajado con los materiales arqueológicos — principalmente cerámicos- para su sistematización (Roldán Gómez,1995a y 1995b), así como una primera valoración de las estructuras medievales. En 1995 se continuaron dichas tareas, se realizaron dos primeros sondeos estratigráficos, uno destinado a contextualizar arqueológicamente el templo principal del foro y otro a determinar la secuencia urbanística y constructiva de los niveles púnicos infrapuestos al foro de la ciudad romana. Por último, se trabajó en la torre almenara, situada al SE. de la ciudad y, sobre todo, en la fortaleza extramuros situada en los terrenos de la actual factoría de CEPSA.

Los trabajos citados, de cuyos resultados trataremos a continuación, suponen el arranque definitivo de un ambicioso Proyecto que pretende valorar arqueológicamente el yacimiento a la vez que convertirlo en un centro de investigación a la altura de la riqueza, patrimonial e histórica, de la ciudad de Carteia. En este sentido, el futuro patrimonial y científico de Carteia cuenta ya con la buena disposición patrocinadora de la compañía CEPSA y, más en particular, de su factoría "Gibraltar", vecina al yacimiento y 
decidida a colaborar en las labores de investigación, mantenimiento y proyección social del yacimiento arqueológico en la esperanza de verlo convertido en referencia de primer orden dentro del Campo de Gibraltar y del patrimonio andaluz y universal en general.

Los dos sondeos realizados se encuentran ubicados en lo que hemos venido en llamar Sectores $B$ y $A$, correspondientes a una zona de ladera de acrópolis y al templo del Foro, respectivamente. El primero de ellos (sector B) está emplazado en la parte suroccidental de la acrópolis, lugar en el que había evidentes posibilidades de poder documentar una significativa superposición estratigráfica asociada a estructuras constructivas de gran interés (lám. 2). Pese a la erosión natural de esta zona de ladera, acentuada por los trabajos realizados para acondicionar los accesos al desaparecido Cortijo del Rocadillo, el sondeo arqueológico ha permitido documentar la superposición de varias fases constructivas bien definidas, punto de partida para la reconstrucción urbana e histórica de la ciudad.

\section{EL SECTOR PÚNICO}

\section{Las estructuras}

Tras la limpieza superficial de todo el sector, la excavación ha permitido constatar varios aspectos de interés, aunque pendientes aún de su definitiva confirmación en próximas campañas. El espacio analizado incluye varias estructuras superpuestas (fig. 4), susceptibles ahora de una ordenación bastante clara, las más antiguas de época púnica, infrapuestas a niveles de ocupación romanos que, en este sector, hay que ponerlos en relación con las estructuras del Foro y, en último extremo, con el templo. Se han diferenciado dos momentos constructivos dentro del período púnico, uno primero constituido por dos muros en esquina de notable regularidad y potencia, levantados con piedras de pequeño tamaño trabadas con tierra e insertados en el suelo natural, una arcilla compacta de color anaranjado (I de la fig. 4). Suponen, pues, el testimonio de la primera ocupación de la ciudad en esta zona. Pronto fueron arrasados por una segunda fase constructiva, mucho más monumental, aunque mantuvo básicamente la orientación de la primera. Lo principal de lo hasta ahora descubierto de ella consiste en muros muy cuidados que delimitan una calle de acceso a la parte alta de la ciudad, uno de ellos cimentado directa, aunque parcialmente, sobre uno de los antiguos (IIa de la fig. 4), mientras el frontero, como otros del mismo momento, abrieron sus zanjas de cimentación directamente en el estrato natural. Este segundo muro, el de la derecha del acceso (II b de la fig. 4), apoya en una zapata de grandes losas de caliza, más ancha que el alzado del muro, en cuya cara superior pueden verse las líneas incisas que, técnicamen- 
lamente, se realizaron estudios centrados en otras manifestaciones culturales tales como la sistematización y valoración de sus emisiones monetales (Chaves, 1979).

A finales de los ochenta se realizaron en el yacimiento nuevas investigaciones sobre la arquitectura y la urbanística de la ciudad. Se encuadraban dentro de un ambicioso proyecto de estudio de la arquitectura hispanorromana desde el punto de vista tecnológico (Bendala, 1992), que estaba por hacer, y que condujo, entre otros frutos, a la publicación de un libro sobre las técnicas constructivas aplicadas en Carteia (Roldán Gómez,1992). Posteriormente, tras una primera campaña de análisis de la documentación y de los materiales arqueológicos procedentes de antiguas excavaciones almacenados en el yacimiento, así como de aquellos depositados en el museo de Sevilla (Roldán Gómez, 1995a), se concibió la puesta en marcha de un ambicioso Proyecto de Investigación bajo los auspicios de la Consejería de Cultura de la Junta de Andalucía, el Estudio bistóricoarqueológico de la ciudad púnicorromana de Carteia (Roldán Gómez, 1995b, e.p.). En él se aborda, de manera integral, el proceso poblacional de Carteia, desde sus primeras etapas históricas, hasta la Edad Media. Se trataba de conocer y profundizar su implantación territorial, la evolución espacial, el desarrollo urbanístico, la caracterización de sus diversas fases constructivas, el estudio de su arquitectura y el conjunto de los materiales arqueológicos. Dirigida la investigación por los dos primeros firmantes de este artículo, cuenta, desde su inicio, con la participación de un amplio equipo de profesores de las Universidades Autónoma de Madrid y Cádiz, especialistas en los diferentes campos culturales contemplados y requeridos por el Proyecto.

\section{LOS TRABAJOS ARQUEOLÓGICOS}

Las tareas de campo han comenzado en 1994 con el estudio de los restos monumentales dispersos por diversos Museos y en el propio yacimiento. Paralelamente, se ha trabajado con los materiales arqueológicos — principalmente cerámicos- para su sistematización (Roldán Gómez,1995a y 1995b), así como una primera valoración de las estructuras medievales. En 1995 se continuaron dichas tareas, se realizaron dos primeros sondeos estratigráficos, uno destinado a contextualizar arqueológicamente el templo principal del foro y otro a determinar la secuencia urbanística y constructiva de los niveles púnicos infrapuestos al foro de la ciudad romana. Por último, se trabajó en la torre almenara, situada al SE. de la ciudad y, sobre todo, en la fortaleza extramuros situada en los terrenos de la actual factoría de CEPSA.

Los trabajos citados, de cuyos resultados trataremos a continuación, suponen el arranque definitivo de un ambicioso Proyecto que pretende valorar arqueológicamente el yacimiento a la vez que convertirlo en un centro de investigación a la altura de la riqueza, patrimonial e histórica, de la ciudad de Carteia. En este sentido, el futuro patrimonial y científico de Carteia cuenta ya con la buena disposición patrocinadora de la compañía CEPSA y, más en particular, de su factoría "Gibraltar", vecina al yacimiento y 
decidida a colaborar en las labores de investigación, mantenimiento y proyección social del yacimiento arqueológico en la esperanza de verlo convertido en referencia de primer orden dentro del Campo de Gibraltar y del patrimonio andaluz y universal en general.

Los dos sondeos realizados se encuentran ubicados en lo que hemos venido en llamar Sectores $B$ y $A$, correspondientes a una zona de ladera de acrópolis y al templo del Foro, respectivamente. El primero de ellos (sector B) está emplazado en la parte suroccidental de la acrópolis, lugar en el que había evidentes posibilidades de poder documentar una significativa superposición estratigráfica asociada a estructuras constructivas de gran interés (lám. 2). Pese a la erosión natural de esta zona de ladera, acentuada por los trabajos realizados para acondicionar los accesos al desaparecido Cortijo del Rocadillo, el sondeo arqueológico ha permitido documentar la superposición de varias fases constructivas bien definidas, punto de partida para la reconstrucción urbana e histórica de la ciudad.

\section{EL SECTOR PÚNICO}

\section{Las estructuras}

Tras la limpieza superficial de todo el sector, la excavación ha permitido constatar varios aspectos de interés, aunque pendientes aún de su definitiva confirmación en próximas campañas. El espacio analizado incluye varias estructuras superpuestas (fig. 4), susceptibles ahora de una ordenación bastante clara, las más antiguas de época púnica, infrapuestas a niveles de ocupación romanos que, en este sector, hay que ponerlos en relación con las estructuras del Foro y, en último extremo, con el templo. Se han diferenciado dos momentos constructivos dentro del período púnico, uno primero constituido por dos muros en esquina de notable regularidad y potencia, levantados con piedras de pequeño tamaño trabadas con tierra e insertados en el suelo natural, una arcilla compacta de color anaranjado (I de la fig. 4). Suponen, pues, el testimonio de la primera ocupación de la ciudad en esta zona. Pronto fueron arrasados por una segunda fase constructiva, mucho más monumental, aunque mantuvo básicamente la orientación de la primera. Lo principal de lo hasta ahora descubierto de ella consiste en muros muy cuidados que delimitan una calle de acceso a la parte alta de la ciudad, uno de ellos cimentado directa, aunque parcialmente, sobre uno de los antiguos (IIa de la fig. 4), mientras el frontero, como otros del mismo momento, abrieron sus zanjas de cimentación directamente en el estrato natural. Este segundo muro, el de la derecha del acceso (II b de la fig. 4), apoya en una zapata de grandes losas de caliza, más ancha que el alzado del muro, en cuya cara superior pueden verse las líneas incisas que, técnicamen- 
te, señalaban la alineación exacta del alzado: un expresivo rasgo del esmero puesto en las construcciones de la segunda fase púnica.

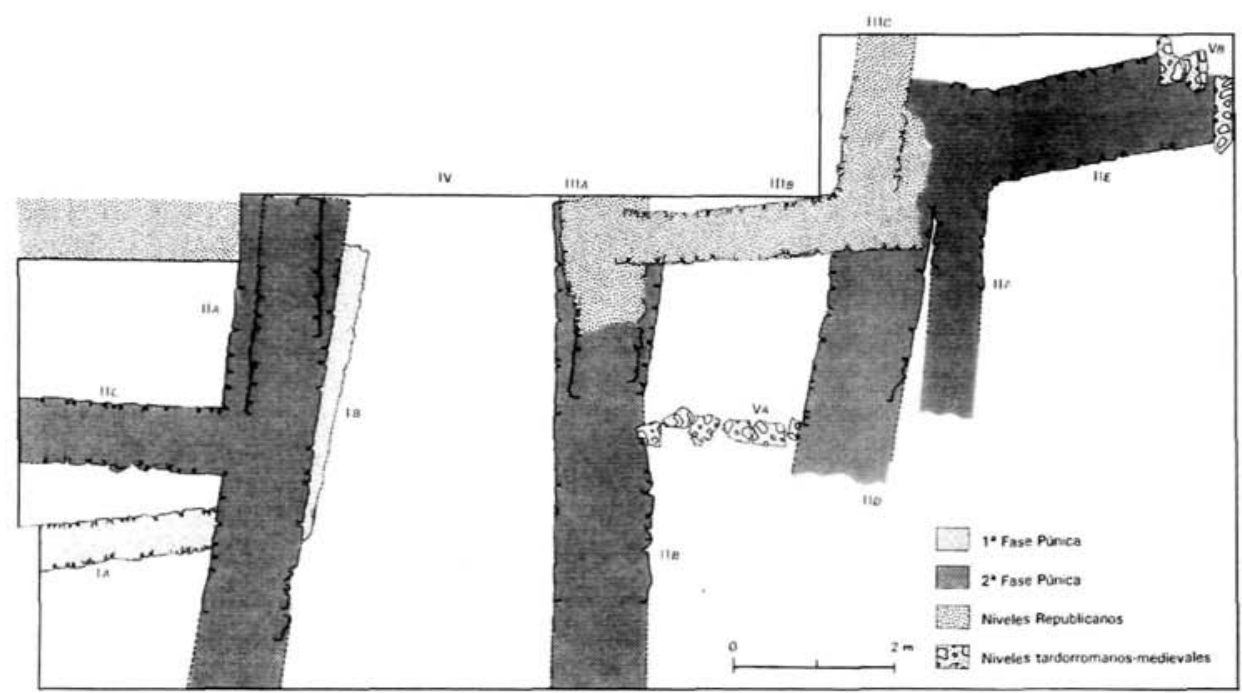

Figura 4. Planta de los muros del sector $B$, o sector de los muros púnicos

Pero lo más significativo de esta fase II, a pesar del pequeño sector excavado, ha sido la exhumación de los dos magníficos muros de sillares ligeramente convergentes que, conservados en más de un metro de altura del alzado original, delimitan lo que parece ser una calle de acceso hacia la parte alta y principal de la ciudad, según se ha dicho. Los paramentos que miran a la calle son de gran calidad, compuestos con sillares de mediano y pequeño tamaño, en ocasiones engatillados, tallados en ligera cuña hacia el interior del muro para trabar mejor en el núcleo (lám. 3). Sus juntas cuidadas, con la inclusión de piezas menores para cubrir espacios, y la frecuente terminación de la cara externa de los sillares con suaves almohadillados confieren a estos dos paramentos de la calle una notable dignidad constructiva. En relación con los dos muros principales, a uno y otro lado de la calle, se levantaron otros dos, ya de menor grosor, que determinan estancias de función imposible de determinar por el momento. El límite oriental del sector excavado coincide con el final, en esquina regular, de los muros de la calle, en un punto en el que será difícil o imposible ampliar el sondeo a causa de la presencia de un triple aljibe romano, que ha roto los niveles arqueológicos anteriores. La calle, cuyo suelo de uso original apoya directamente en el nivel geológico natural, tiene $3 \mathrm{~m}$. de anchura y se ha descubierto un recorrido de $6 \mathrm{~m}$. entre lo conservado de los muros. Todo lo documentado, en conjunto, supone un acceso al sector alto de la ciudad púnica de notable monumentalidad, que quedaría con posterioridad amortizado en época romana. 
La importancia urbanística y constructiva de esta segunda fase, así como la continuidad posterior, son claros indicios de la envergadura del proyecto de la nueva ciudad y la prueba de su éxito. Se llevó a cabo no mucho después de la primera, según parece en fechas pendientes de precisar en próximas excavaciones, entre finales del s. IV y el s. III a.C. La cuidadosa fábrica de los muros que delimitan la calle, descritos más arriba, responden a una técnica constructiva de raigambre griega muy característica de los ambientes púnicos helenísticos, como se comprueba en Cartago, Lixus, Sala, Tamuda, Sulcis, Motia o Volúbilis. Referencias más cercanos las encontramos en algunos muros del Castillo de Doña Blanca (Puerto de Santa María, Cádiz) correspondientes a la fase púnica de la ciudad y fechados en este mismo momento de los siglos IV-III a.C. (Ruiz Mata,D.,1993).

La estratigrafía del sondeo permite comprobar el proceso de colmatación de la calle (lám. 5, fig. 5) en un largo uso de la misma y, ya en cuanto a cuestiones constructivas, un muy posible alzado último de sus muros con adobes, que aparecen en número significativo en el potente estrato de relleno que cierra el segundo y, por el momento, último momento púnico. La amortización del espacio elevó en torno a un metro el suelo de uso en aquella zona y, sobre ella, aparece una tercera fase reconocible por nuevos restos de muros, fundamentalmente sus cimientos, que profundizaron en la masa de escombros anteriores. Sin embargo, éstos siguieron en lo esencial el trazado antiguo, tanto en su apoyo directo sobre los muros púnicos amortizados (muros IIIa, b y c; fig. 4), como en su orientación general y el mantenimiento de la calle. Esta Fase III ofrece mucho menos rigor constructivo y, aunque lo documentado hasta el momento es poco, vale para comprobar lo antes apuntado: el mantenimiento de la orientación de los muros y del uso de la calle. La tercera fase fue luego amortizada por otra posterior que, esta vez sí, cambió de modo radical el planteamiento urbanístico en —al menos- este sector de la ciudad. La antigua calle, como se comprueba en la zona inmediata al sector estudiado, fue cubierta por una casa con atrio cuyo aljibe ahuecó la acumulación estratigráfica de fases anteriores lo que, tal y como comentábamos, dificultará futuras ampliaciones del sondeo.

Esta última casa, correspondiente ya a la Fase IV, y aun pendiente de un estudio en detalle, tal vez podría encuadrarse en época altoimperial, mientras que la anterior - la fase III- con mayor seguridad parece corresponder a una remodelación de época republicana fechable en la segunda mitad del siglo II a.C., quizá en momentos avanzados de la misma. Así lo apuntan algunos fragmentos de barniz negro (Campaniense B) aparecidos en la fosa de cimentación de uno de sus muros (IIIa de la fig. 3) como, por ejemplo, un borde de plato (F-7 Lamb.; serie 2283 de Morel) fechable entre el 140-120 a.C. (Morel, J. P., 1981,p.161; lám. 44), (fig. 6).

\section{El Sector púnico: los materiales}

En el estado actual de la investigación y a la espera de continuar los trabajos arqueológicos, ya en extensión, dentro del área que hemos denominado sector púnico, tanto el material aparecido en labores de limpieza, como el de excavación, evidencian 


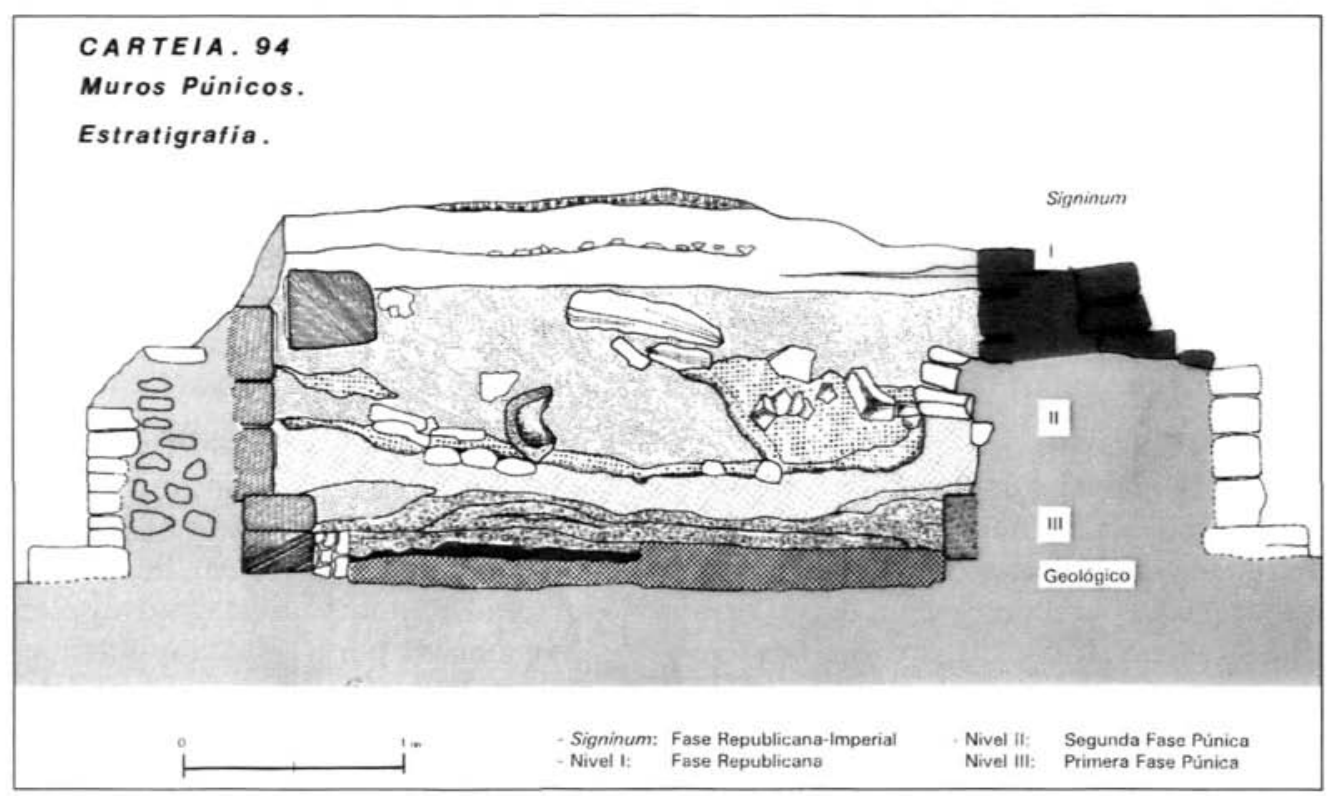

Figura 5. Estratigrafia del sector púnico, Campaǹa de 1994. Estrato I: relleno de época republicana; estrato II: amortización del periodo púnico; estrato III: uso de la calle en el período púnico

una notable coherencia a la hora de su interpretación cultural. Así, habría una 1. a fase púnica (fig. 5), inicio ocupacional del nuevo asentamiento al menos en el sector excavado, a la que se asocian cerámicas comunes y, más precisables cronológicamente, cerámicas de barniz negro, en concreto fragmentos del pie y fondo de un plato ático de posible F-21 con detalles formales que apuntan una datación en torno al primero, o comienzos del segundo, cuarto del siglo IV a.C. (fig. 7 , núms. 8 a 10). A continuación, y prácticamente sin solución de continuidad, habría una 2. a fase (fig. 5), tambien púnica por el momento, igualmente asociada a materiales de barniz negro de notable antigüedad y de Kouass, algo más modernos, que ratifican el valor post quem de los primeros para el conjunto de la zona y del yacimiento. Se pudo excavar con minuciosidad parte de la fosa de fundación del muro monumental derecho de la calle (IIb de la fig. 4) y enella aparecieron dos fragmentos significativos de barniz negro. Uno de ellos asimilable de nuevo a una F-21, acaso una F-22, con decoración de palmetas; el otro, un fondo de kylix posiblemente del tipo aborde vertical" y pie bajo con cronología similar al anterior, es decir, $1 .^{\circ}$ cuarto del s. IV a.C. (fig. 6, núms. 4 y 5 ).

Otro punto de apoyo para la cronología de la 2." fase púnica ha sido el material aparecido en el estrato III del sondeo estratigráfico, identificable con el uso de la calle a lo largo del tiempo (fig.5). Encerraba numerosos fragmentos de barniz negro y del tipo Kouass, igualmente significativas pero hasta el momento poco estudiadas en la Península 


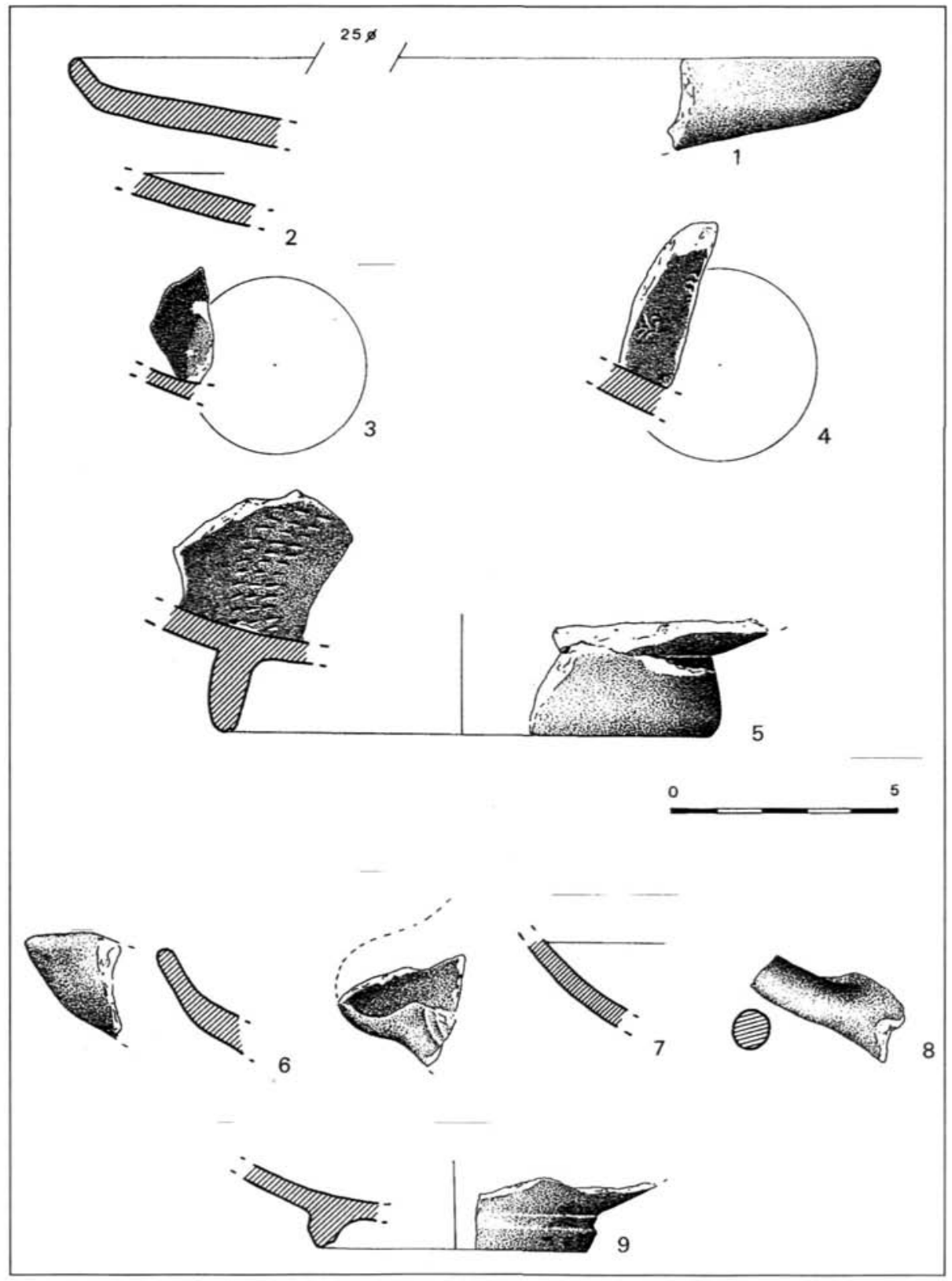

Figura 6. Materiales de harniz negro de las fosas de fundación y de tipo Kouass 


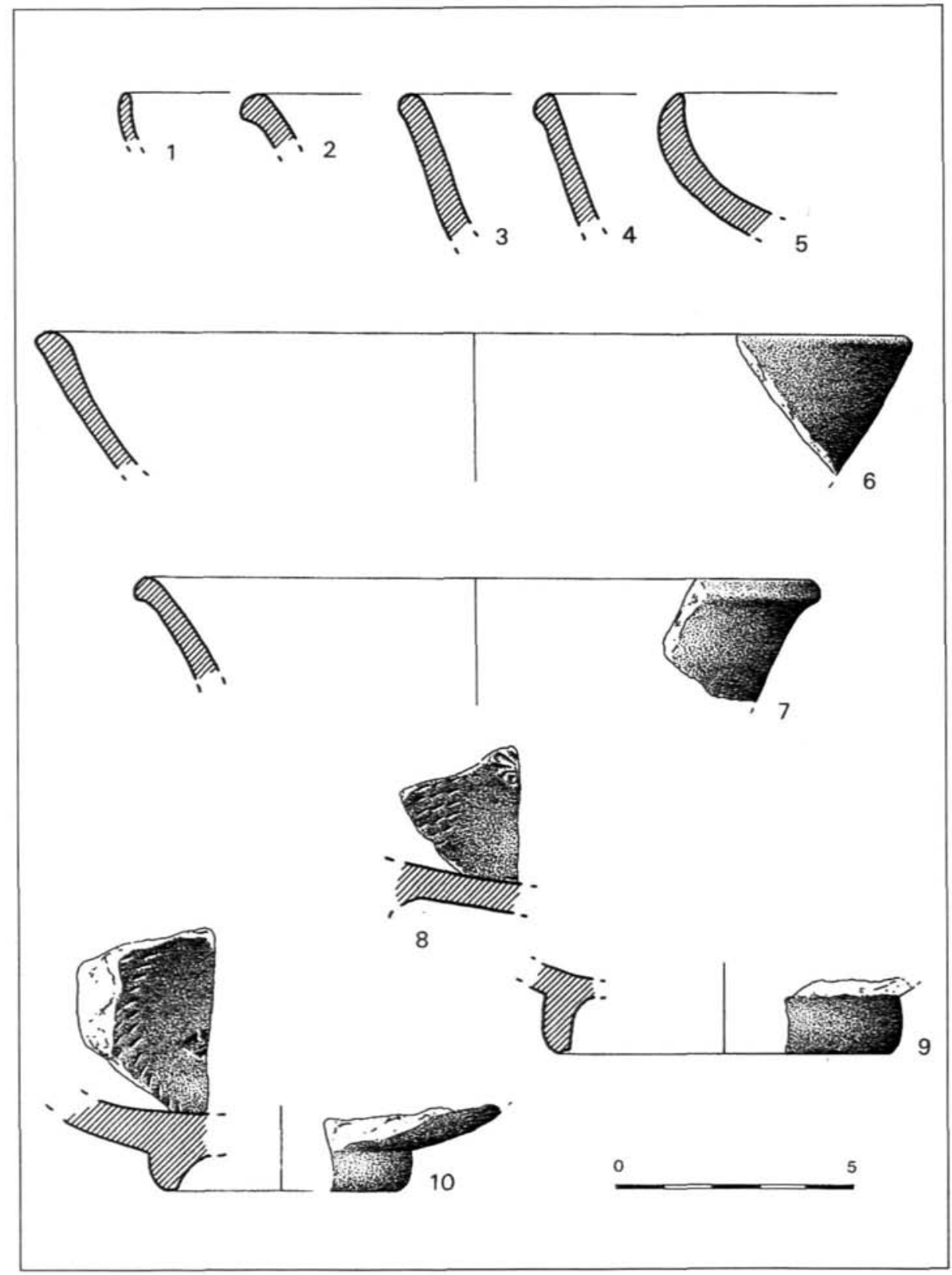

Figura 7. Materiales de harniz negro del perfil estratigráfico 
(Ponsich, 1968 y 1969; Blánquez,1985; Ruíz Mata,1996). La cerámica de barniz negro incluye fragmentos de vasos áticos, de nuevo formas 21 o 22, junto a otros de procedencia itálica, algunos de ellos con decoración de ruedecilla y palmeta de cuño: un cuenco de la F-27 y un borde de plato del tipo 2977 de Morel, que se pueden fechar a partir de la $2{ }^{a}$ mitad del s. II a.C. (Morel, 1981, 242; lám.83), (fig. 7). Por lo que respecta a los fragmentos de tipo Kouass siguen las pautas características de estas producciones: imitación de la tipología helenística y un acabado mediante engobe rojizo. En esta ocasión se han documentado variantes de platos de pescado, un fragmento de lucerna y otro más de kylix propios de las producciones de los ss. IV-III a.C. (fig. 6, num.6 a 9).

\section{El Sector púnico. Conclusiones}

La posibilidad de una ocupación de Carteia desde el s. IV a.C. ya había sido sugerida, con anterioridad, en trabajos de otros investigadores (Woods,1969; Presedo, en Corzo Sánchez dir. et alii, 1983, 31), pero ahora, con la estratigrafía documentada, puede afirmarse con mayor seguridad, así como detectar en la secuencia urbanística ahora obtenida la importancia de esa fase inicial. Parece deducirse que ya entonces y por dos veces consecutivas se procedió a una planificación de la ciudad que, en su segundo momento, responde a un proyecto de particular envergadura, como sugieren la contundencia de sus muros y el sistema constructivo empleado. Todo ello, en su conjunto, influiría de manera determinante en el proceso urbanístico posterior, tal y como refleja el seguimiento de su trazado en fases posteriores

Se ratifica, por otra parte, su correlación con el vecino yacimiento de El Cerro del Prado (lám. 4) y su traslado a lo que sería la definitiva Carteia (fig. 8). El primitivo asentamiento fenicio fue fundado a mediados del s. VII a.C. y, según los datos arqueológicos conocidos, abandonado hacia la mitad del s. IV a.C. (Pellicer et alii, 1977; Ulreich et alii, 1990). Ahora, con las conclusiones obtenidas sobre la antigüedad de la primera fase de Carteia, parece confirmarse la idea de un traslado de la población desde el asentamiento primitivo al nuevo, sin solución de continuidad y probablemente manteniendo el nombre de Carteia que pudo ya tener el asentamiento fenicio originario del Cerro del Prado. Es más, las razones tradicionalmente aducidas en torno al cambio poblacional a causa de la colmatación de la desembocadura del Guadarranque, que daría al traste con el carácter portuario de este inicial asentamiento (Arteaga et alii, 1988; Schubart, 1993), pueden hoy aceptarse y matizarse con nuevas consideraciones. El estudio paleoambiental y paleotopográfico del asentamiento urbano de la Carteia púnica, ahora iniciado dentro del Proyecto, está dando ya resultados significativos. La reconstrucción iniciada de la loma sobre la que asentó la nueva ciudad, elegida según criterios de larga tradición feniciopúnica, permitía nuevos planteamientos urbanos y urbanísticos en un lugar que posibilitó, en principio, duplicar prácticamente el espacio disponible en relación con el asentamiento primitivo. Este hecho, junto a la envergadura urbanística del nuevo emplazamiento desde sus primeras fases, aconseja valorar al máximo la existencia de un pe- 
ríodo de auge comercial como motor de un proyecto de una ciudad portuaria de mayor nivel, determinante, junto a los condicionamientos topográficos, del nacimiento de la nueva Carteia.-

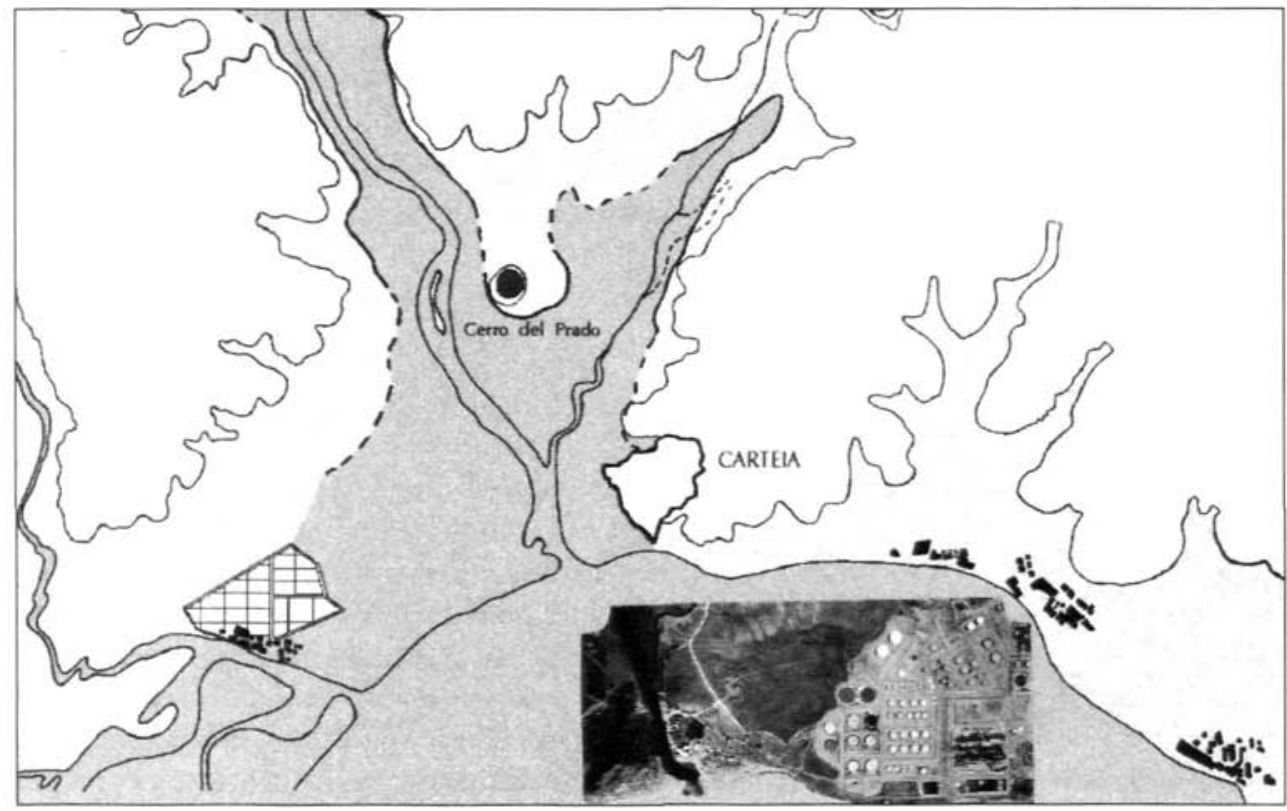

Figura 8. Mapa de reconstrucción de la bahia de Algeciras en época púnica (según Schubart y Hoffman). Ampliado hipotéticamente según la cota $+20 \mathrm{~m}$.

En efecto, en el marco de la consolidación del dominio púnico en el Mediodía hispano cabe pensar en un traslado que, a un tiempo, resolviera los problemas derivados de una ubicación cada vez menos conveniente por razones geográficas, y ocupara un nuevo emplazamiento más adecuado a las expectativas de un proyecto urbano más ambicioso. Debió de producirse, por tanto, un fenómeno frecuente en el proceso de maduración de las organizaciones urbanas, por el que las ciudades, definidas fundamentalmente como un conjunto de ciudadanos cohesionados por un patrimonio histórico, espiritual, económico y político común, pueden desplazarse sin pérdida de su propia identidad en función de proyectos de emplazamiento territorial adecuados a las previsiones colectivas, un fenómeno que se repetiría con frecuencia en la ola de maduración urbana impulsada con la conquista romana, según vamos conociendo mejor en los últimos años (Bendala,1990a; Abad y Bendala,1995).

El conjunto de cerámicas encontradas en las fosas de fundación de los muros excavados, así como en la estratigrafía del sondeo, no cierran definitivamente la cuestión cronológica. Su no muy elevado número supone una limitación cuantitativa y cualitativa 
a paliar en próximas excavaciones. Sin embargo, materiales y estructuras, tratadas de manera conjunta, demuestran su notable importancia urbanística y la intensa actividad constructiva y económica que la ciudad en época púnica debió de tener, asentada definitivamente en el solar de la que luego sería la Colonia Libertinorum Carteia.

\section{EL SECTOR DEL FORO}

En la actualidad y en relación con el área del foro se conoce, tan sólo, una pequeña parte correspondiente al templo monumental, situado en la plataforma superior, y el inicio de la gran plaza que se extendería originalmente delante de él (fig. 9). Hasta hace pocos años la plaza aun estaba ocupada, en su mayor parte, por dependencias del cortijo de El Rocadillo y permanecía, prácticamente, sin excavar. Se conoce, por otra parte, un gran acceso monumental escalonado que uniría esta plaza con las estructuras de la plataforma inferior. El templo de Carteia situado en la parte mas alta del foro es, pues, su monumento arquitectónico más representativo.

El resto de las estructuras visibles del foro se organizan en dos plataformas unidas por la gran escalera monumental. En la parte inferior se reconocen tabernae y diversas habitaciones de funcionalidad desconocida, mientras que, en la plataforma superior presidida por el templo monumental y sus accesos, parecen existir varias residencias, realizadas y reformadas en sucesivas etapas

\section{El templo}

El edificio es de planta cuadrangular, de 18 x $18 \mathrm{~m}$., que conserva in situ, únicamente, los muros del podium coronados por una moldura de cyma reversa en parte restaurada (fig. 10); su orientación este-oeste no sigue exactamente la del acceso monumental escalonado del foro, ni de las estructuras de la plataforma superior. La construcción se llevó a cabo sobre una cimentación de piedras irregulares de tamaño medio y pequeño, con abundante argamasa de unión, mientras que su alzado se hizo ya con grandes mampuestos bien acoplados entre sí de tamano irregular y escuadrados al exterior, al menos así se ha podido documentar en la cara exterior del podium conocida a través de antiguas excavaciones. En ocasiones se utilizaron lajas, de unos $4 \mathrm{~cm}$. de gro- 


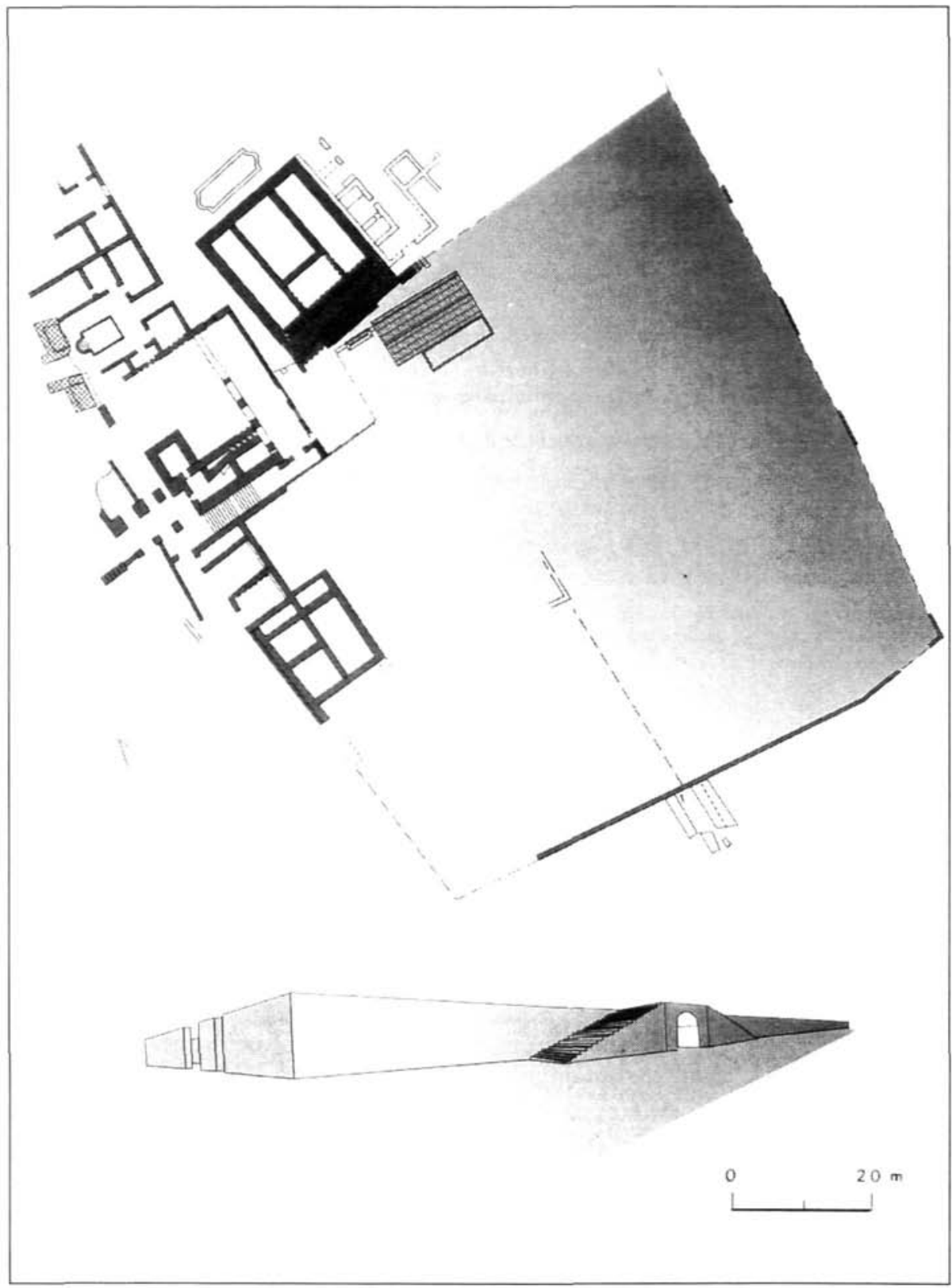

Figura 9. Reconstrucción ideal del espacio del Foro (según L. Roldán Gómez). 
sor, para encajar mejor unas con otras y mantener la horizontalidad. Se conservan restos de un revoco del muro del podium en su lado derecho.

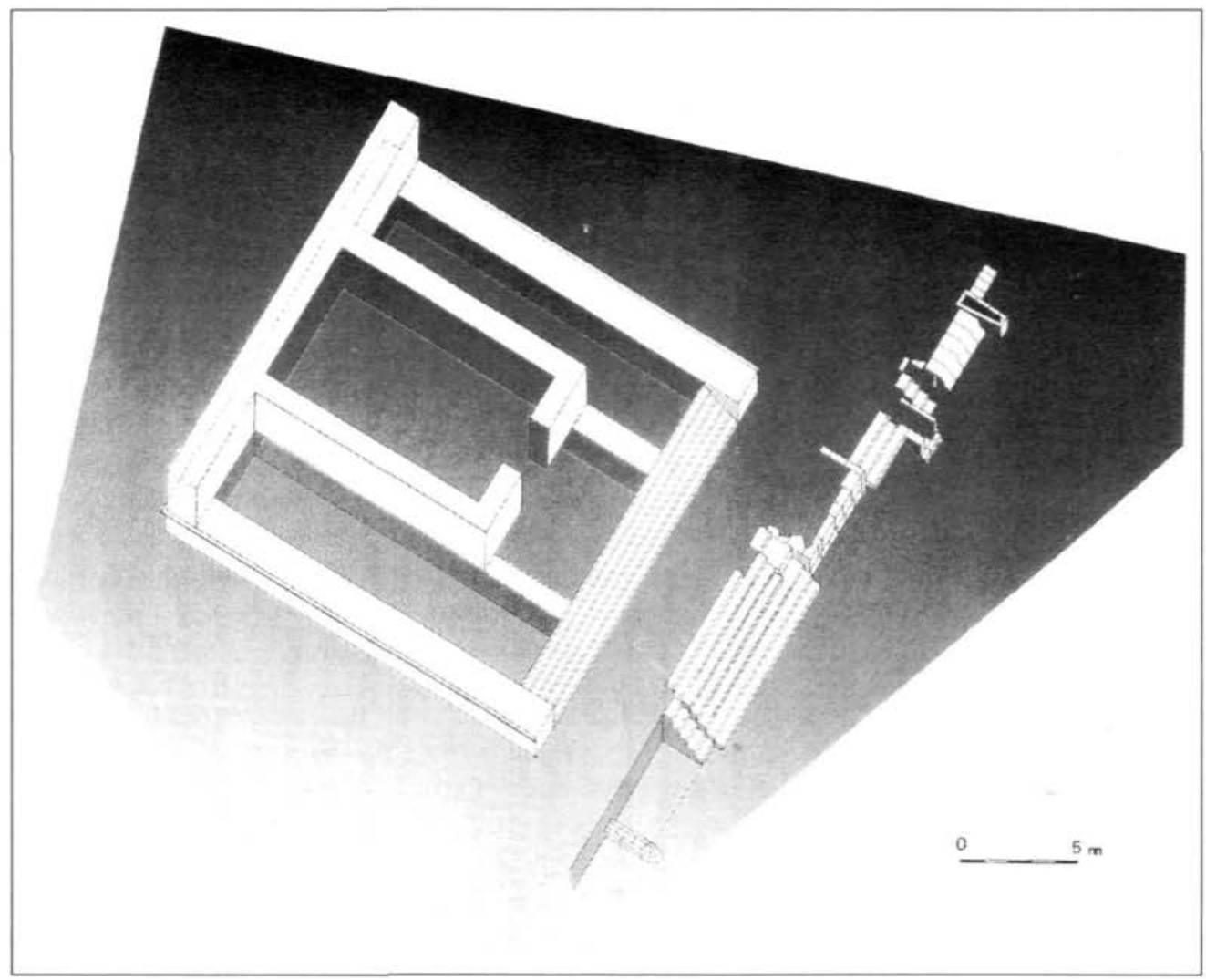

Figura 10. Reconstrucción parcial del templo del Foro (según L. Roldán Gómez)

Los muros de compartimentación interna, de menos grosor, están realizados en opus vittatum con piedras de menor tamaño. Sobre la planta pueden verse alteraciones de época tardía que modificaron por completo su estructura cuando había perdido su carácter originario de templo; se trata de estructuras realizadas en el interior de la cella y en las alae, con técnica de inferior calidad. Asimismo, la fisonomía original quedó transformada por enterramientos medievales, realizados en gran parte con materiales reutilizados o aprovechando estructuras existentes, que se colocaron en el interior del podium, en los laterales del templo e invadiendo por completo el acceso frontal (Presedo et alii, 1982). Originalmente, dicho acceso estaría compuesto por dos tramos de es- 
caleras de los que sólo se conserva el inferior, que abarcaba el ancho de la cella. El superior, que es obligado dada la diferencia de altura entre el final de la escalinata conservada y el podium del templo, podría ser del mismo ancho u ocupar sólo la parte central.

La cronología del edificio se estableció a finales del s. I a.C., considerando que se trataba de un Capitolio, es decir, un templo de triple cella dedicado a la triada capitolina. Sin embargo, esta adscripción carece de fundamento arquitectónico (Bendala, 1989-90), ya que, en lo que hasta ahora hemos podido conocer, se trata de un templo de tipología muy antigua, de cella única con alae laterales (Roldán Gómez, 1992), semejante al templo C de Largo Argentina en Roma, de finales del s. IV a.C. (Gatti 1982, 61), al templo septentrional del Foro Olitorio, aún mas antiguo, o al templo de Juno en Gabii (AlmagroGorbea, 1982).

En el entorno del templo se conservan aún algunos de sus elementos arquitectónicos y decorativos, reutilizados o amontonados en construcciones posteriores, bien ya en tumbas medievales o, incluso, rodados por las proximidades, todos en caliza fosilífera estucada (lám. 6). Otras más y de igual o mayor interés se encuentran depositadas en el Museo de Sevilla en un montaje arquitectónico aproximado de cómo pudo ser el levantamiento original (lám. 7). Se trata, en el primero de los casos, de columnas estriadas rematadas por capiteles corintizantes y prótomos de toro, así como cornisas decoradas alternativamente con palmetas, rosetas y prótomos de toro igualmente, que nos acercan a la riqueza decorativa original del edificio.

\section{Los elementos arquitectónicos}

Un primer análisis de algunos de estos elementos basta para comprobar la gran monumentalidad del templo al que correspondieron, labrados en la habitual piedra fosilífera de la zona - muy usada también en la vecina Baelo Claudia-, tallada aquí con cierto detalle antes de ser estucada y pintada como acabado final, exigencia ineludible con el uso de estos materiales para obtener la dignidad arquitectónica adecuada a un gran templo.

Las basas se componen, en general, de dos toros desiguales separados por una escocia encuadrada por filetes, y están rematadas en la parte superior por un caveto con listel en su base. Presentan parte del imoscapo tallado en la misma pieza, con una altura total de $54 \mathrm{~cm}$. y un diámetro en el imoscapo de $64 \mathrm{~cm}$. Es un tipo de basa frecuente en la primera arquitectura hispanorromana (Jiménez, 1975), una forma antigua caracterizada por la ausencia de plinto, incorporado habitualmente desde la época de Sila, aunque también se utilizan basas sin plinto en cronologías posteriores, hasta bien entrada la época imperial (Chiner Martorell, 1990, 89), según se comprueba en la propia Hispania (Bendala, 1990b, 200-205). La presencia de listeles encuadrando la escocia aparece a finales del s. II a.C., aunque la moldura (escocia) es aún pequeña. Dicha moldura va to- 
mando cuerpo a lo largo del s. I a.C. y llega a ocupar, junto con el toro superior, una espacio más grueso que el de la moldura inferior, constituyendo el perfil ático característico del final de la república y comienzos del Imperio (Chiner Martorell, 1990, 89).

Los capiteles, tallados en dos bloques distintos, corresponden al tipo llamado corintizante por Ronczewski (1923). Se trata de una variante del orden corintio con las volutas formadas por elementos vegetales, por lo que también se les ha llamado de volutas vegetales. Siguen en su mayoría el esquema de un kálathos redondo o rectangular con las volutas de los ángulos formadas por las mismas hojas, a veces con una roseta en su interior (Gutiérrez Behemerid, 1992, 183-84). Esta variante del corintio se da, según Ronczewski, con cierta frecuencia desde comienzos de época de Augusto y durante los siglos I y II d.C.

Quizás los elementos más peculiares son los de gran tamaño en forma de prótomo de toro, algunos de cuyos ejemplares se conservan en el yacimiento y otros en el museo de Sevilla y en el de San Felipe (San Roque, Cádiz). Este tipo de ornato no fue muy frecuente, pero toros arrodillados a guisa de capiteles fueron utilizados, por ejemplo, en el Pition de Delos, construido hacia mediados del s. III a.C.: componían el remate de dos pilastras que flanqueaban el vano central del adyton (Littleton, 1988, 54); asimismo, fueron utilizados prótomos de toros como metopas en los intercolumnios de la Stoa de Antigono en Delos (Lawrence, 1957,264 y 267) también de la mitad del s. III a.C. (Dinsmoor, 1950,290-292).

Elementos peculiares del templo de Carteia son también las piezas de dinteles adovelados que se conservan en el yacimiento y en el museo de Sevilla. En éste último se han presentado como elementos intermedios entre las columnas y el arquitrabe - tenidos inicialmente por posibles triglifos- pero se trata, como dijimos, de piezas de dintel que, una vez montadas, dejaban ocultas las juntas oblicuas en una compleja disposición técnica en la forma elegida para la imbricación y la sujeción de los elementos del dintel (Jiménez, 1984, 15, fig. 2 y 3 ).

\section{Los trabajos arqueológicos en el templo}

Los trabajos de excavación en el área del foro, dada su extensión y complejidad, se han limitado en las dos primeras campañas (1994 y 95) al entorno del templo; primero reanalizando un corte realizado por el Prof. Presedo en la parte trasera del podium, limpiando y comprobando sus perfiles. Se ha podido con ello contemplar el inicio de la cimentación del citado podium, a 1,50 m. bajo la cornisa de remate, lo que indica para aquél una altura relativamente baja en relación con los templos romanos.

Los datos estratigráficos obtenidos en este corte no permiten determinar la cronología del edificio, ya que la excavación no había profundizado hasta los niveles fundacionales; no obstante, sí se ha podido observar cómo los niveles de amortización de esta 
estructura muestran cierta complejidad, ya que proporcionan materiales muy diversos, aunque en su mayoría de época imperial. Entre ellos se encuentra, por ejemplo, un ánfora púnica del s. III a.C. que probablemente proviene de momentos anteriores a la gran construcción.

De mayor interés ha sido el análisis de la relación estratigráfica entre el templo y el mal llamado baptisterio situado a su espalda, en realidad un estanque seguramente sin relación con el templo y de construcción claramente posterior a la de éste último. Su suelo de uso, al margen ahora de precisiones en cuanto a cota, inutilizaría ya gran parte del alzado del podium del templo y la observación detallada del signinum de su obra, con fragmentos de sigillata clara D, pone de manifiesto la realización tardía de la misma. Aún con todo, quedan problemas por resolver, como la posible existencia de otra construcción similar, anterior a ésta, y coetánea a la construcción del templo; el nivel concreto del suelo de uso del estanque, con seguridad muy por encima del que corresponde al templo; precisar las muy posibles remodelaciones de su estructura, etc.

Por todo lo anterior, en la campana de 1995 se han realizado dos nuevos cortes estratigráficos perpendiculares al podium del templo, a uno y otro lado del muro oriental del mismo (lám. 8, 9 y 10). La complejidad y potencia de los niveles documentados, así como las numerosas estructuras aparecidas, no han permitido finalizar su excavación, por lo que los resultados y comentarios que pasamos a exponer son por fuerza provisionales. La estratigrafía, leída de abajo a arriba, y los materiales aparecidos dentro de las misma parten de los niveles prerromanos, púnicos, y continúan hasta la época imperial. En el sondeo situado en el interior del podium (lám. 10), en el que se ha profundizado más, se han podido diferenciar por el momento dos niveles. En el primero de ellos, el inferior, han aparecido varias estructuras murarías realizadas con piedras grandes e irregulares; a éstas se asocian cerámicas prerromanas: pintadas púnicas, comunes de mesa y fragmentos anfóricos. A continuación, y tras sucesivos niveles de utilización y aplanamiento, se ha documentado la terminación de una estructura realizada en opus signinum u hormigón hidráulico, aún sin definir, asociable a un momento púnico o republicano antiguo, aunque con seguridad anterior al nivel II, bien fechado ya con cerámicas de barniz negro del tipo campaniense, cerámica común y material anfórico que caracterizan bien este nivel segundo. Posteriormente, aunque sin haber transcurrido un gran período de tiempo, se llevó a cabo la construcción monumental templaria. Su zanja de cimentación, al menos por su cara interna, por el momento la única descubierta, no fue muy profunda aunque rompió los estratos del nivel II. De modo inmediato se rellenó la fosa y el espacio circundante hasta conseguir la altura deseada de la cella, a 1,50 m. por encima de la calle en aquél momento. Poco se puede precisar, por ahora, de los momentos sucesivos, ya que la estructura del edificio y los niveles posteriores aparecen arrasados (lám. 11), incluso por debajo de los niveles de relleno que se colmatarían en el momento en que se construyó el templo.

En el sondeo realizado al exterior del podium (lám. 9), la construcción de un muro adosado al mismo a todo lo largo de su cara norte en un momento todavía no precisable, 
cuando el espacio que lo rodea no había sido colmatado, plantea interesantes problemas aún sin resolver satisfactoriamente; con una cimentación en torno al metro de profundidad, su alzado está realizado con mampuestos de caliza que alternan regularmente con grandes bloques de caliza fosilífera. Pero todo lo concerniente a la particular historia constructiva del templo y sus inmediaciones, habrá de esperar hasta que avancen adecuadamente las excavaciones en este sector.

\section{EL PERÍODO MEDIEVAL}

El estudio del período medieval se ha centrado, fundamentalmente, en dos sectores independientes; por un lado, en la torre almenara, conocida popularmente como "Torre Cartagena" (lám. 12) y ubicada en el extremo suroriental de la ciudad; por otro, en un pequeño recinto fortificado situado extramuros de la ciudad romana, a unos $450 \mathrm{~ms}$. al NE del teatro romano y en lo que hoy son terrenos de la vecina refinería de CEPSA (lám. 13). En el primero de ellos, la tarea abordada se ha centrado en la realización de su representación planimétrica: secciones y alzados, y plantas de las diversas estancias internas de la torre, de todo lo cual nos ocuparemos en otro momento y lugar. Trataremos aquí con más detalle de la fortaleza, en la que se ha procedido al levantamiento de plantas y alzados y a una fructífera prospección arqueológica de su emplazamiento.

\section{El recinto fortificado}

El entorno original de la fortaleza se encuentra hoy totalmente modificado a causa de las numerosas obras llevadas a cabo por la factoría. Depósitos, antorchas y diversos caminos de servicio han hecho que sea una verdadera fortuna el que se haya preservado, casi intacto, el perímetro fortificado. Las citadas obras han alterado también los desniveles naturales sobre los que se alzaría el castillo, otorgándole una clara finalidad al mismo. Sin embargo, por textos y grabados antiguos (Carter,1981,41 y 46 y Romero de Torres, 1909, 252-253), sabemos que la topografía original proporcionaba al recinto una situación más destacada y preeminente.

Poca documentación se ha podido recoger de trabajos anteriores, descripciones poco concisas que, sin embargo, permiten conocer su denominación original. En concreto, Romero de Torres nos habla de un castillo ó torre llamada de Cartagena (1909, 252). El "castillo" en cuestión corresponde a una estructura fortificada de planta cuadrangular, de 31 x 30 ms., por su cara interna, si bien algo más irregular al exterior como consecuencia del adosado de algunas estructuras como el acceso en codo y la torre albarrana (fig. 11). 


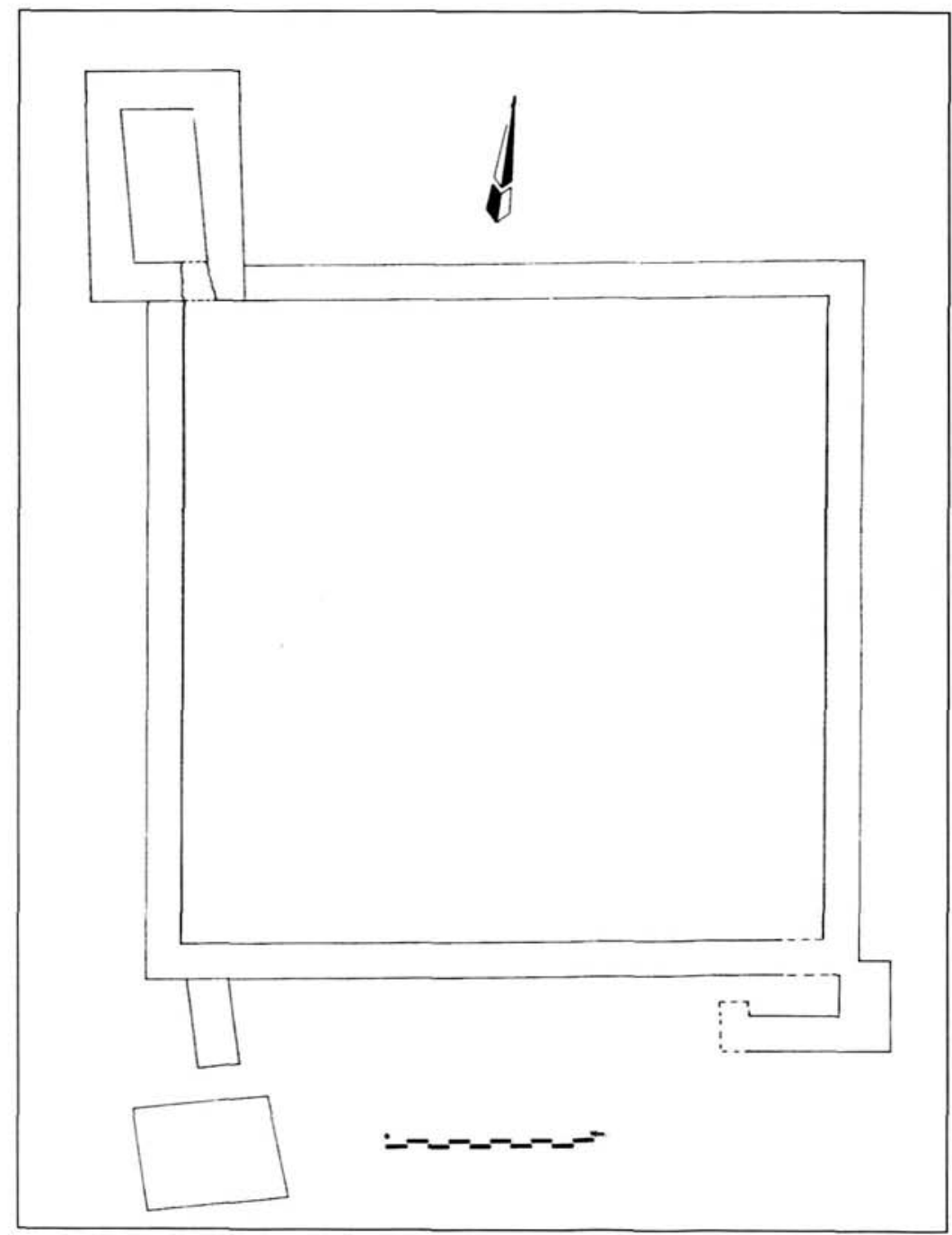

Figura 11. Planta del castillo medieval en terrenos de la factoría CEPSA

Torre albarrana

Corresponde a un ejemplo de planta cuadrangular $(6,50 \times 5 \mathrm{~m}$. aproximadamente), se encuentra ubicada en el ángulo suroeste de la fortificación, que aprovecha la afloración rocosa del terreno a cuyo relieve irregular se adapta perfectamente. Como toda construcción de este tipo, la existente en este recinto parte de un lienzo, en este caso el meridional, 
y se proyecta al exterior casi $6 \mathrm{~ms}$. si se cuenta la luz del arco que la separaba de la fortaleza. La construcción está realizada en obra de mampostería, con sillares de tamaño mediano al exterior, que alternan con hiladas estrechas de lajas. Las esquinas, bastante deterioradas en los cuatro ángulos, se plantearon mediante sillares de piedra colocados por sus lados largo y corto, alternativamente. Por su cara norte se reconoce todavía el arranque del arco que permitía la comunicación del lienzo con la torre albarrana, lienzo que estaba formado por dos hiladas superpuestas de ladrillos de mediano tamaño.

El aparejo está trabado con mortero de argamasa de tonalidad pardo-rojiza, tal vez a causa de la contaminación del entorno. Como componentes significativos del mortero de argamasa, destaca la presencia de fragmentos machacados de teja y ladrillo. El acabado final fue mediante un enlucido que recubría el paramento exterior, pero sólo se conserva en algunos puntos. El interior de la torre es macizo, realizado con distintos tipos de piedra trabadas con un mortero de argamasa.

\section{Acceso en codo}

En el ángulo sureste del recinto se ubicó el acceso al interior de la fortaleza (lám.14). Embutido dentro de una pequeña estructura rectangular, obligaba a realizar un giro de $90 .^{\circ}$ para acceder al interior y es, por el momento, el único punto de entrada conocido. El lado oriental se realizó mediante sillares y mampostería de mediano tamaño, lajas de pizarra degradada y piedras de pequeño tamaño; todo ello unido con mortero de argamasa formando hiladas alternas de sillares y lajas de pizarra. El paramento interior de este mismo lado ofrece las mismas características que el paramento exterior. Al sur se abría un vano del que todavía se reconoce su esquina oriental, mientras que la occidental se ha perdido casi totalmente. Este hueco interior fue cerrado en época posterior utilizando el mismo tipo de material que el antiguo paramento interior del muro sur, pero con una argamasa ya diferente. Por el contrario y hasta el momento, no se han documentado las estructuras que cerrarían el bastión por su lado oeste.

\section{Almenara}

Por último, en el ángulo noroeste del recinto fortificado se ha documentado otra estructura de planta rectangular de, aproximadamente, $7 \times 11 \mathrm{~m}$., adosada a los lienzos norte y oeste del citado recinto. Su finalidad constructiva, en el estado actual de la investigación, no es del todo segura, sin embargo posiblemente se trate de los restos de una antigua almenara a la que, con posterioridad, se le habría anadido el recinto fortificado. No olvidemos a este respecto que los muros sur y este de nuestra hipotética atalaya no traban con el recinto amurallado, simplemente están adosados. Por otro lado, y para esta misma cuestión, hay que tener en cuenta que los textos del s. xvII hablan y reco- 
nocen una "torre Cartagena" asociada a un "castillo" (Carter, 1981,46 y Romero de Torres,1909,252) que Hernández del Portillo define como ... una torre o castillo que en su fábrica bien parece obra antigua aunque los moros la repararon sin que se le eche de ver ser obra morisca (Torremocha, 1994,119).

El material constructivo con que está realizada, como la casi totalidad del recinto, es una combinación de sillares, lajas y sillarejo regular. Los primeros, de caliza fosilífera en su mayoría, dispuestos en la parte inferior (lado sur) pero, conforme se asciende en altura, el número de lajas y sillarejo aumenta en la clara intención de ir elevando el paramento mediante hiladas horizontales. Sin embargo, en el lado occidental, el paramento se plantea con la alternancia de una hilada de lajas y una de sillares de mayor o menor tamaño, pudiéndose tal vez hablar de un encintado de lajas". En la parte baja puede reconocerse la ya mencionada existencia de sillares de mayor tamaño.

El interior de los muros corresponde a un relleno formado por sillarejo, pequeños sillares, lajas y mampostería irregular, todo ello trabado con mortero de argamasa en la actualidad fácilmente degradable. Hoy en día, la superficie exterior presenta restos originales de dos tipos de enlucido, deducibles por sus distintas tonalidades, blanco y castano-anaranjado, respectivamente. En el interior de la estructura todavía son reconocibles dos estancias correspondientes a dos niveles sobrepuestos. El inferior, mejor conservado mantiene levantada parte de su cubierta abovedada, hecha de ladrillo; la superior, mientras, conserva sólo parte de los muros de su perímetro rectangular.

\section{Los materiales}

El material cerámico obtenido corresponde, por el momento, a prospecciones planteadas en todo el exterior de la fortificación. Han aparecido cerámicas bizcochadas con decoraciones con trazos de pintura en manganeso; vidriados melados y melado y negro; manganeso y, por último, algunos fragmentos de cuerda seca parcial. Se encuentran en la actualidad en fase de estudio, pero plantean ya hipótesis de trabajo acerca de los moradores de la mencionada fortificación.

Entre los fragmentos bizcochados recogidos una de las formas más representativas ha sido el alcadafe, pieza ésta de gran diámetro que tiene a veces la superficie interior engobada en tonos rojizos (almagra) y posteriormente alisada (bruñida), con una gran tradición en la vajilla doméstica de al-Andalus desde los tiempos de la dinastía omeya. En algunos fragmentos de los recuperados alrededor del castillo de Carteia encontramos una decoración de pequeñas incisiones a lo largo del borde, en su parte exterior; la misma solución alfarera la vemos en algunos yacimientos del entorno gaditano como Beca (Cavilla, 1992a, 127, fig. 7.3); Fīsāna-Faysāna (Abellán y Cavilla, 1993,26-27) y la propia Cádiz (Aranda, 1994,126-127). También está presente en yacimientos magrebíes como Ceuta (Fernández Sotelo, 1988); Qașr aș-Ṣagșr (Redman, 1983, fig. 3); 
Badis (Redman, 1983-1984, fig. 26); Basra (Redman, 1983, fig.5) y Nakūr (Redman, 1983-1984, fig. 29).

Los fragmentos pintados sobre superficie bizcochada son minoritarios, si bien asociados a tipos cerámicos muy claros y conocidos, como son los casos de los jarros y jarras. Presentan decoraciones de estrechos trazos de manganeso dispuestos en pinceladas paralelas y acabado redondeado. Se reconocen también y sobre formas similares en el cercano y ya citado yacimiento de Barbésula, San Roque, (Cavilla,1992b,65) y en el más alejado, pero también de ámbito litoral, de Silves, Portugal (Varela,1993,47). Un paralelo más para este tipo de decoración, pero ya del mundo pleno-medieval levantino, es el caso de la alquería de Bofilla, en Valencia (López Elum,1994,343) si bien para éste último, así como el de Silves, los tipos cerámico corresponden a tapadera y olla, respectivamente. Esta decoración de trazos pintados es muy posible que siguiesen la tradición anterior de similares ejemplos del mundo omeya andalusí, aunque reduciéndose el tamaño y tonalidad del trazo.

Dentro también de acabados bizcochados, y en ciertos casos vidriado al interior, encontramos algunos fragmentos que presentan una carena muy acentuada en su parte inferior, obteniéndose unas bases de perfil convexo. Corresponden a tipos cerrados como jarras, jarros y marmitas, con claros paralelos en los yacimientos ya comentados, añadiendo, entre otros, el vecino de Bullones (Belyounech, Marruecos) (Grenier, 1980, 234-235), el onubense de Saltés (Bazzana, Bedía y Meulemeester, 1994, 114) y los más alejados de Almería (Flores y Muñoz, 1993, 126) y Murcia (Navarro, 1991, 114-124).

Pasando al mundo de las piezas vidriadas, hay que indicar en primer lugar que son minoritarias respecto a las bizcochadas, observándose un importante predominio del tipo ataifor en sus distintas variantes (Roseló, 1978 y 1991). Se documentan con claridad tanto los tipos de perfil carenado - tipo I-, como los de perfil curvo. Como paralelos más claros en bordes, carenas y bases, podemos citar los conjuntos aparecidos en Bullones (Grenier, 1980, 228), Qasr al-Sagīr (Redman, 1983, fig. 3), Barbésula (Cavilla, 1992b, 61), Castellar de la Frontera (Sotomayor, 1993, 12) y Mértola (Torres, 1986, 202).

Por lo que respecta a las formas documentadas en superficie en la fortaleza medieval de Carteia vemos que predominan las abiertas: ataifores de paredes rectas y oblicuas; cazuelas; platos; escudillas y alcadafes. Por el contrario, son algo menos abundantes las cerradas: jarras y jarros; ollas; orzas; redomas y "canecos".

\section{El periodo medieval. Conclusiones}

Aun estando el estudio monográfico de la fortaleza en proceso de realización, podemos apuntar algunas propuestas en torno al posible origen y cronología de esta cons- 
trucción. El reducido tamaño de la torre albarrana y su proximidad al lienzo del recinto fortificado nos recuerda a ciertos ejemplos de pequeñas fortalezas almohades en al-garb al-Andalus como Paderne (Albufeira, Portugal), estudiado últimamente por H. Catarino (1994, 81). Paralelamente, el planteamiento de acceso en codo se reconoce en ciertas fortalezas de pequeño tamaño existentes en el cercano litoral onubense como Lepe y Saltés, y que autores como A. Bazzana y P. Cressier asocian a "mano de obra" almohade (Bazzana y Cressier, 1989, 43-46). El resto del recinto fortificado de Carteia nos recuerda en su planta a los ya comentados recintos de Lepe (supra,46) y Saltes (supra,44), junto al gadinato de Cartaya (supra,46) y al marroquí de Madīnat al-Safi (Cressier, 1995, 178). Por último, el aparejo nos recuerda también a ciertas estructuras preportuguesas del vecino yacimiento de Qašr as-Ṣaīr (Redman, 1983 y 1983-1984).

A la hora de otorgar una cronología al conjunto de materiales e insistiendo en su carácter provisional, dado su proceso de estudio, observamos que las cronologías propuestas en los yacimientos peninsulares anteriormente citados se centran en el momento de ocupación almohade, si bien los distintos autores que se han ocupado de los magrebíes apuntan una posterior tradición meriní. Por nuestra parte pensamos que los materiales cerámicos más significativos recogidos en prospección corresponden a los momentos en que el poder almohade, y posteriormente el meriní ocuparon este entorno.

Así pues, parte de la ocupación de esta fortaleza se debió dar desde fines del siglo XII hasta, por lo menos, finales del siglo xIV, por lo que se refiere al contexto islámico. Sin embargo y sin ser contradictorio, existen también documentos (Torremocha, 1994, 117-119) que nos hablan de la "reutilización" de esta pequeña fortaleza por parte de distintos "poderes cristianos" en los siglos XIV y XV (rey de Castilla, duque de Medina Sidonia y conde de Jerez), aspecto éste que esperamos poder valorar en próximas excavaciones.

\section{BIBLIOGRAFÍA}

ABAD, L., y BENDALA, M., 1995: “Urbanismo y ciudad: de las formaciones ibéricas a la consolidación del modelo romano", XXIII Congreso Nacional de Arqueología, Elche (e.p.)

Abellán Pérez, J., y Cavilla Sánchez-Molero, F., 1993: "Fīsāna Faysāna o Hq.y.s. na, un despoblado altomedieval en la cora de Sadūna", Al-Andalus-Magreb, I, pp. 13-49.

Almagro-Gorbea, M., 1982: El santuario de Juno en Gabii. Excavaciones de 1956-1969, Roma.

ARANDA LiNARES, C., 1994: "La cerámica musulmana del teatro romano de Cádiz", Boletín del museo de Cádiz, VI, pp. 125-142.

ARTeaga, O.; Hoffman, G.; Schubart, H., y Schulz, H. D., 198: -Investigación geológicoarqueológicas a lo largo de la costa del Mediterráneo, M.B. 14. 
Bazzana, A., y Cressier, P., 1989: Shaltīsh/Saltés (Huelva). Une ville médiévale d'al-Andalus, Madrid.

Bazzana, A.; Bedia García, J., y De Meulemeester, J., 1994: "Shaltish (Huelva-Espagne) une ville dans les marais", Archéologie islamique, 4, pp. 87-116.

Bendala, M., 1989-90: "Capitolia Hispaniarum”, Anas 2-3, pp. 11-36.

- 1990a: "El plan urbanístico de Augusto en Hispania: precedentes y pautas macro territoriales", Statdbild un Ideologie, München, pp. 25-42.

- 1990b: La Antigüedad. De la Prehistoria a los visigodos, vol. I de la Introducción al Arte Español, Madrid.

- 1992: "Materiales de construcción romanos: peculiaridades de Hispania", Ciencias, metodologías y técnicas aplicadas a la arqueologia, Barcelona, pp. 215-226.

BLÁNQUEZ, J., 1985: “Un nuevo material cerámico de engobe rojo”, VI Congreso Internacional de Arqueología Submarina (Cartagena) 1982, Madrid, pp. 463-474.

CARTER, F., 1981: Viaje de Gibraltar a Málaga (1777). Diputación de Málaga, Málaga.

Castelo Ruano, R.; Cardito Rollán, L. M.; Panizo arias, i.,y Rodríguez Casanova, i., 1995: Santa-Olalla, crónicas de la cultura arqueológica española, Madrid.

Catarino, H., 1994: "O castelo de Paderne (Albufeira): resultados da primera intervençào arqueológica", Arqueologia Medieval, 3, Campo Arqueológico de Mértola, Mértola, pp. 73-87.

CAVIlla SÁnChez-Molero, F., 1992a: La cerámica hispano-musulmana de Beca (Los Caños de Meca, Barbate, Cádiz), Universidad de Cádiz, Cádiz.

- 1992b: "La cerámica islámica de Barbesula (San Roque, Cádiz). Apuntes sobre las producciones almohades del suroeste peninsular", Boletín del Museo de Cádiz, V, pp. 55-66.

Corzo SÁnchez, R. (Dir) et alii, 1983: San Roque. Historia de los pueblos de la provincia de Cádiz, Cádiz.

Cressier, P., 1995: "La fortification islamique au Maroc: éléments de bibliographie", $A r$ chéologie islamique, 5, pp. 163-196.

Chaves Tristán, F., 1979: Las monedas hispanorromanas de Carteia, Alicante.

Chiner Martorell, P., 1990: La decoración arquitectónica en Saguntum, Valencia.

DinsmOOR, W. B., 1950: The Architecture of ancient Greece, Londres 1950.

Fernández Sotelo, E. A., 1988: Ceuta medieval. Aportación al estudio de las cerámicas (s. $X-X V)$, Ceuta. 
Flores escobosa, I., y MuÑoz Martín, M. ${ }^{a}$ M., (Coord.) 1993: Vivir en al-Andalus. Exposición de cerámica (s. $I X-X V)$, Almería.

GATTI, E., 1982: "Area sacra di Largo Argentina", Roma Republicana tra il 509 e il 270 a.C., Roma. pp. 26-36.

GRENIER DE CARDENAL, M., 1980: "Recherches sur la céramique médiévale marrocaine", $L a$ céramique médievale en méditerranee occidentale, Valbonne, 11-14 septembre, 1978, París, pp. 227-249.

Gutiérrez Behemerid, M. A., 1992: Capiteles Romanos de la Península Ibérica, Valladolid. Hernández del. Portillo, A., 1994: Historia de Gibraltar, Algeciras.

JimÉnEZ, A., 1975: “De Vitruvio a Vignola: autoridad de la tradición”, Habis 6, pp. 253-293.

- 1984: "Notas sobre dovelas engatilladas", Cuadernos de la Construcción 8, Escuela Superior de Arquitectura, Sevilla, pp. 15-20.

LAWRENCE, A. W., 1957: Greek Architecture, Londres.

LiTtLeton, M., 1988: La arquitectura barroca en la antigüedad clásica, Madrid.

LÓPEz ElúM, P., 1994: La alquería islámica en Valencia. Estudio arqueológico de Bofilla. Siglos $X I$ a $X V$, Valencia.

MOREL, J. P., 1981: "Alfarería de época fenicia y púnico-mauritana en Kouass (Arcila, Marruecos)", Papeles del Laboratorio de Arqueología de Valencia, 4.

Navarro PAlazón, J., 1991: Una casa islámica en Murcia. Estudio de su ajuar (siglo III). Murcia.

Pellicer, M., y otros, 1977: „Para una metodología de localización de colonias fenicias en las costas ibéricas: el Cerro del Prado", Habis 8, pp. 217-251.

PEMÁn, C., 1942: "Memoria sobre la situación arqueológica de la provincia de Cádiz", 1940, I.M., 1.

PONSICH, M., 1969: "Les ceramiques d'imitation: la campanienne de Kouass", A.Esp.A., 42, pp. 56-80.

PrESEDO, F., 1977: -Excavaciones en Carteia, San Roque (Cádiz), 1973", N.A.H., 5, pp. 131-136

PRESEDO, F. y otros, 1982: Carteia, E.A.E 120, Madrid.

PRESEDO, F., y A. CABAllos, 1988: "La ciudad de Carteia: estado de la cuestión y primeros resultados de la campaña de 1985, I Congreso Peninsular de H. ${ }^{a}$ Antigua, II, Santiago de Compostela, pp. 509-519.

REDMAN, C. L., 1983: "Comparative urbanism in the Islamic Far West", World Archaeology, vol.14 n. ${ }^{\circ}$, pp. 355-377.

- 1983-1984: "Survey and test excavation of six medieval islamic sities in northern norocco", Bulletin d'Archeologie Marocaine, t.XV, pp. 311-349. 
ROLDÁN Gómez, L., 1992: Técnicas constructivas romanas en Carteia (San Roque, Cádiz), (Monografías de Arquitectura romana 1), Madrid.

- 1995a: „El Proyecto de Investigación Estudio Histórico arqueológico de la ciudad Hispano-romana de Carteia. Desarrollo arquitectónico y urbanístico de la ciudad ", III Jornadas de Historia del Campo de Gibraltar, pp. 93-107.

- 1995b: “Aproximación al desarrollo arquitectónico y urbanistico de la ciudad punico romana de Carteia (San Roque, Cádiz)", XXIII C.N.A, Elche, e.p.

ROMERO DE TORRES, E., 1909: "Las ruinas de Carteia", B.R.A.H., 54, pp.247-253.

- 1934:Catálogo Monumental de la provincia de Cádiz (1908-1909), Madrid.

RONCZEWSKI, 1923: “Variantes de chapiteaux romains”, Acta Universitatis Latviensis, VIII, 1923.

ROSELlÓ-BORBOY, G., 1978: Ensayo de sistematización de la cerámica árabe en Mallorca, Palma de Mallorca.

- 1991: El nombre de las cosas en al-Andalus, Palma de Mallorca.

RUIz MATA, D., 1993: Los fenicios de época arcaica -siglos VIIVVII a.C.- en la babia de Cádiz. Estado de la cuestión, Instituto oriental, Lisboa.

- 1996:" Situación actual de la investigación sobre los turdetanos : materiales y cronología". Revista de Estudios Ibéricos 2, Madrid (e.p.).

SCHUBART, H., 1993: «Investigaciones geológicas y arqueológicas sobre la relación costera de los asentamientos fenicios en la Andalucía mediterránea", Alvar, J., y Blázquez, J.M., (eds.), Los enigmas de Tarteso, Madrid, pp.69-80.

SOTOMAYOR Muro, M., y SOTOMAYOR Rodríguez, N., 1993: “Excavaciones arqueológicos en Castellar de la Frontera", Almoraima 10, Noviembre, pp. 7-19.

TORREMOCHA SILVA, A., 1994: Algeciras entre la cristiandad y el islam, Algeciras.

TORRES, C., 1986: "Um lote cerâmico da Mértola islâmica", I Congreso de Arqueología Medieval Española, IV, 193-228, Zaragoza.

Ulreich, H.; Negrete, M. A.; Puch, E., y Perdigones, L., 1990; "Cerro del Prado. Die Ausgrabungen 1989 im Schulthang der phönirischen Ansiedlung am der Guadarranque-Mündung", M.M. 31, pp.194-250.

VARELA GOMES, M., 1993: "Cerâmicas muçulmanas: quais as metodologias arqueológicas?", Actas das 1. ${ }^{a}$ Jornadas de Cerâmica Medieval e Pós-Medieval, Lisboa, pp. 41-50.

Woods, D., y otros, 1967: Carteia, E.A.E. 58, Madrid.

wOODS, D., 1969: “Carteia and Tartessos”, V Symposium de Prebistoria Peninsular, (Jerez de la Frontera 1968) Barcelona. 


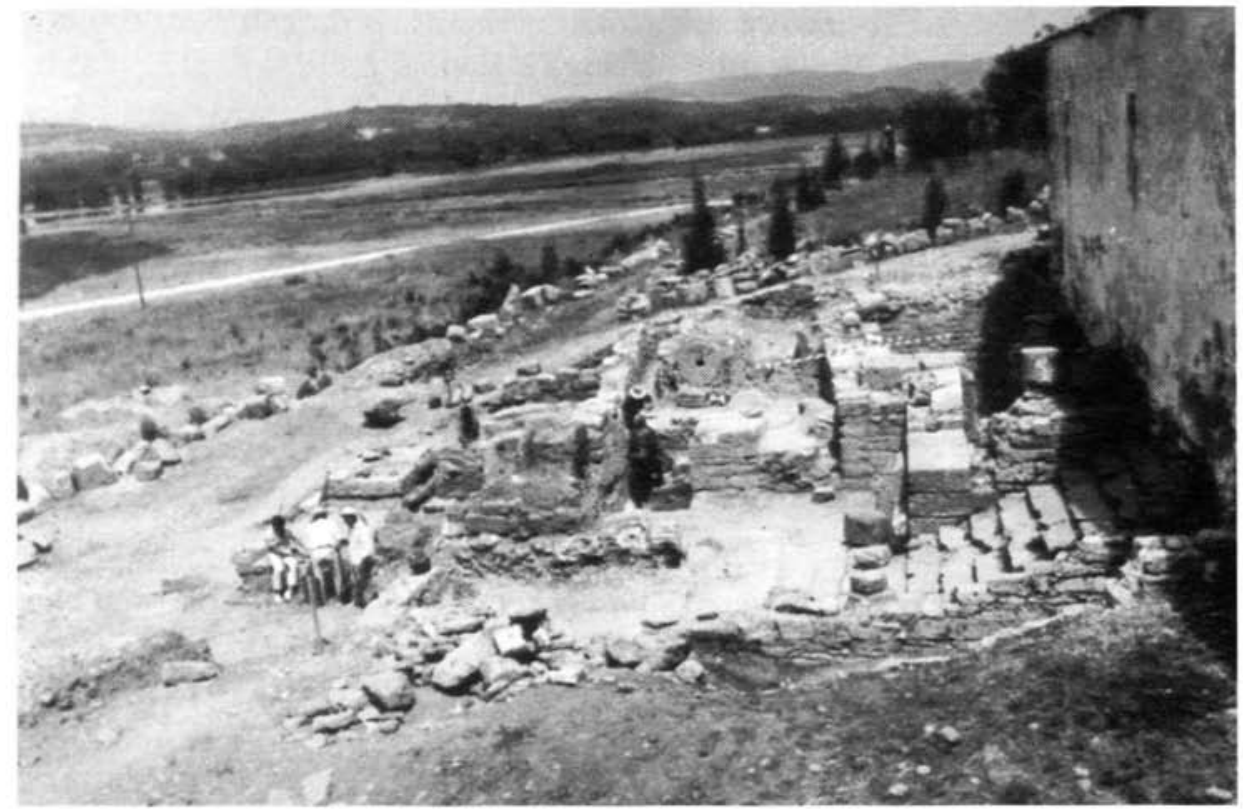

Lámina 1. Excavaciones en Carteia (1967) junto a las estructuras del Cortijo de El Rocadillo superpuestas

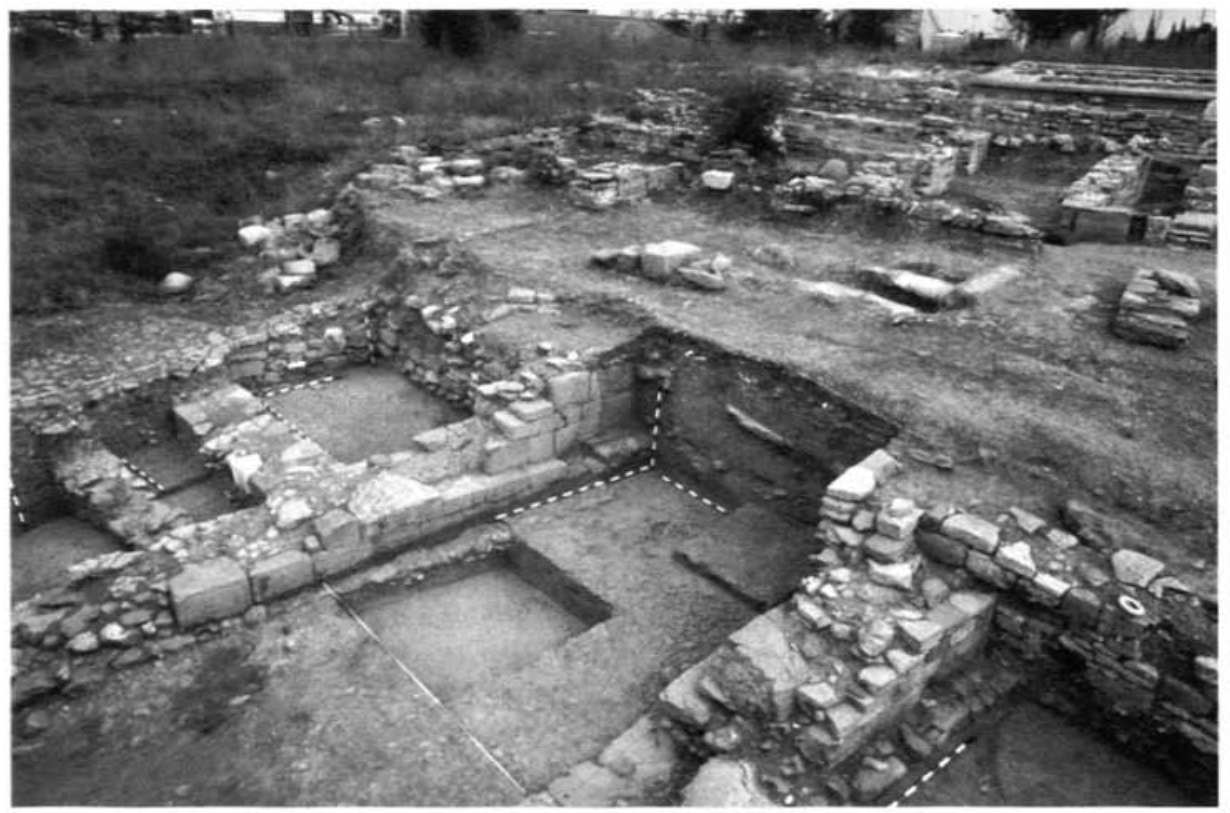

Lamina 2. Vista general del Sector Púnico en las excavaciones de 1994-95 


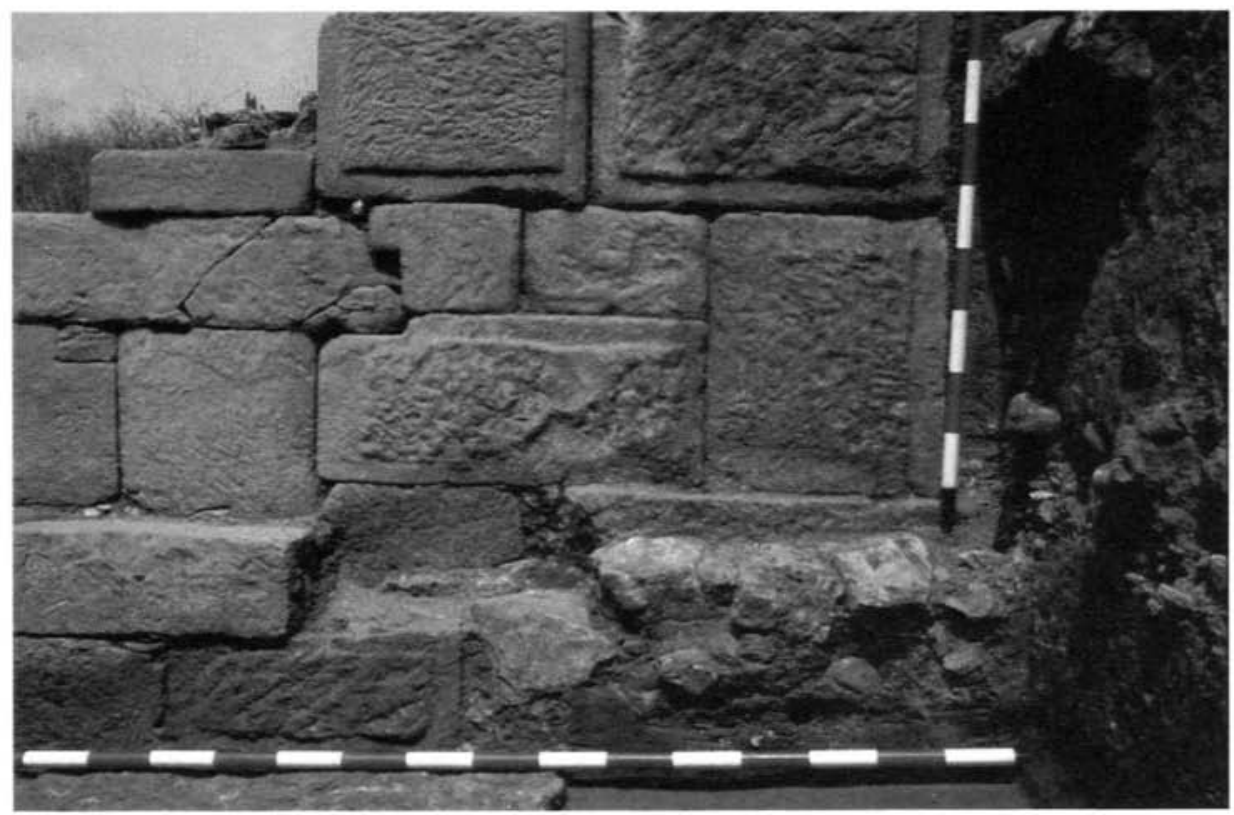

Lámina 3. Detalle del muro púnico del $2 .^{\circ}$ momento de la ciudad

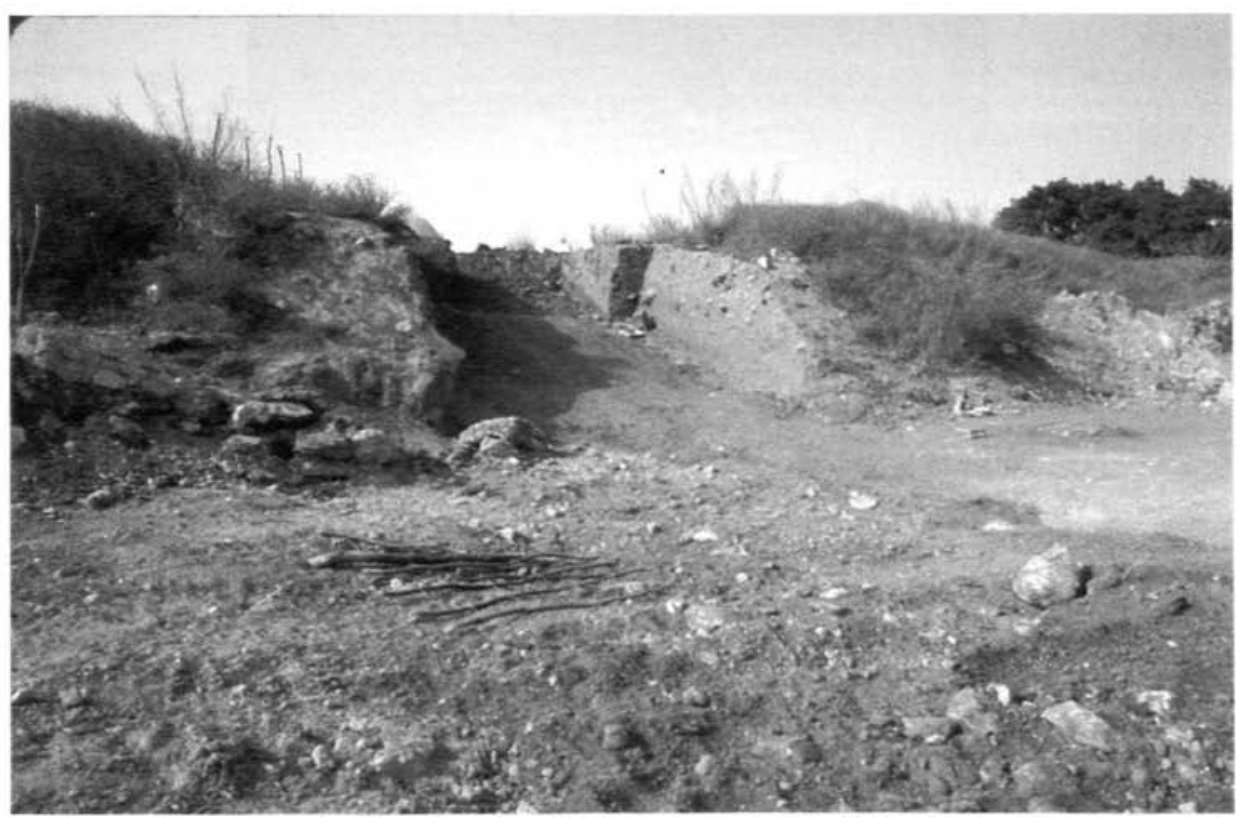

Lámina 4. Vista parcial de El Cerro del Prado, con los cortes en la ladera de las excavaciones de 1989 


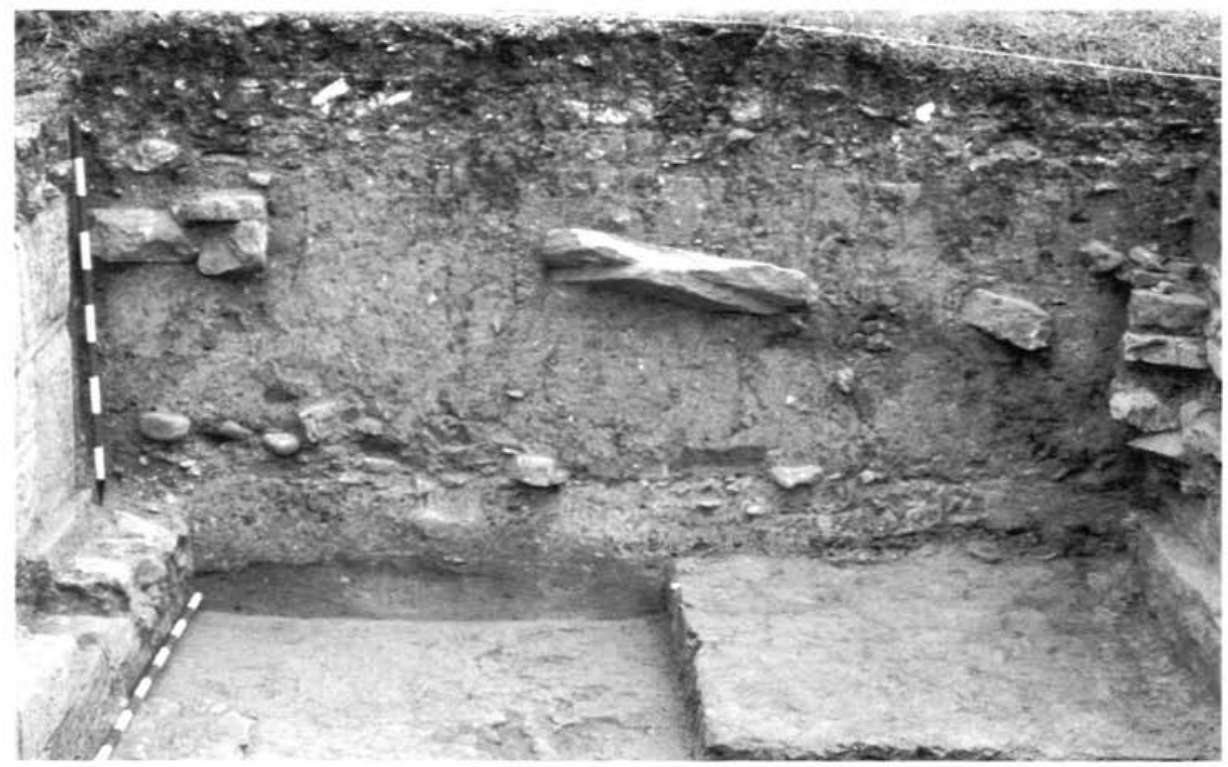

Lämina 5. Perfil del Corte Estratigráfico. Sondeo de 1995

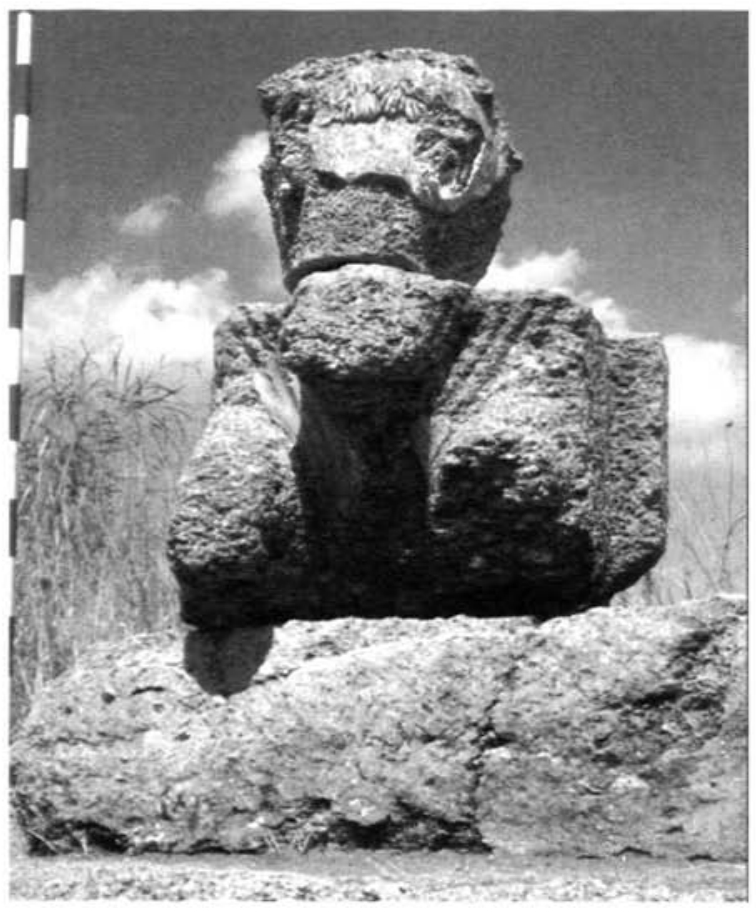

Lámina 6. Flementos arquitectónicos de la superestructura del templo actualmente en superficie 


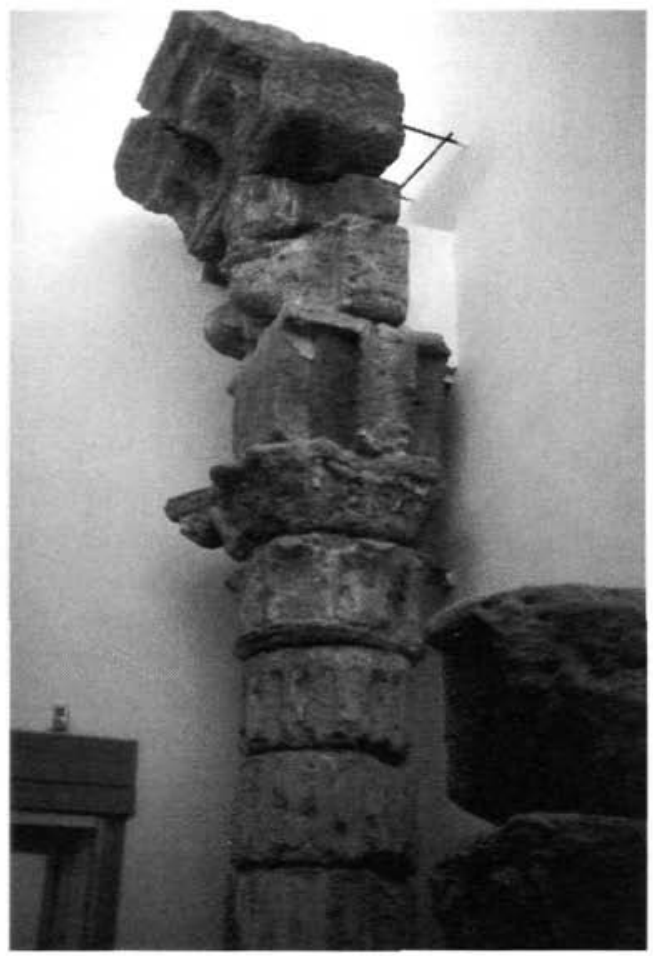

Lámina 7. Reconstrucción del orden arquitectónico del templo en el Museo Arqueológico de Sevilla

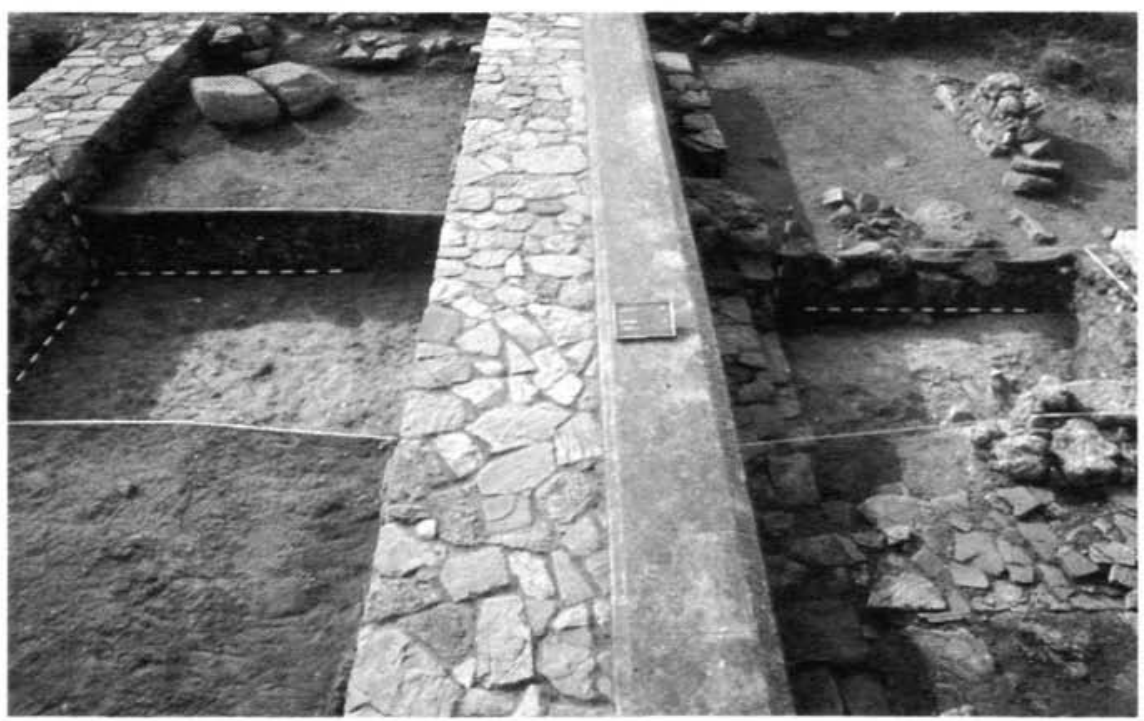

Lámina 8. Cortes estratigráficos del Sector Romano, área del templo 


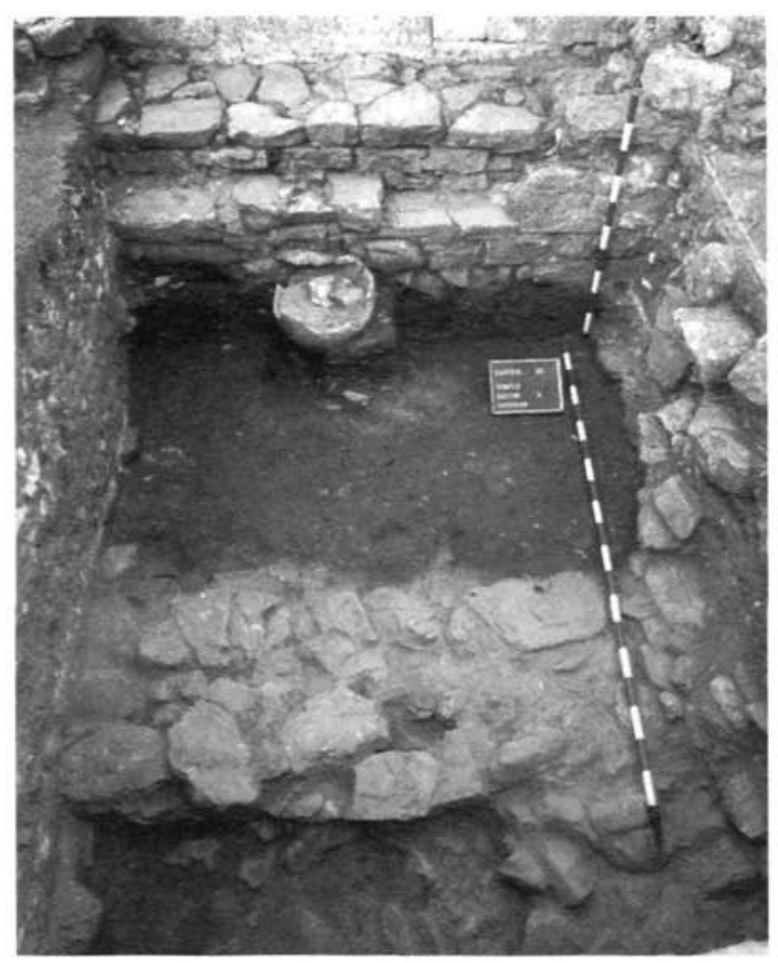

Lámina 9. Detalle de la excavación del sondeo exterior del podium del templo (1995)

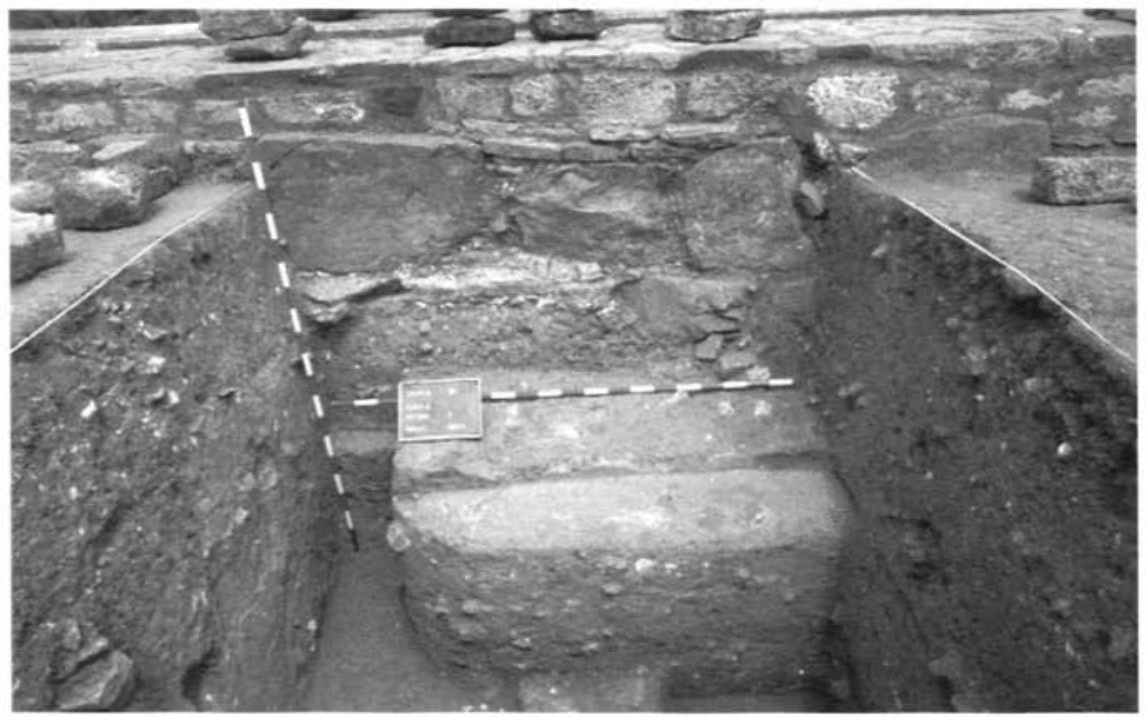

Lámina 10. Detalle de la excavación del sondeo en el interior del podium del templo (1995) 


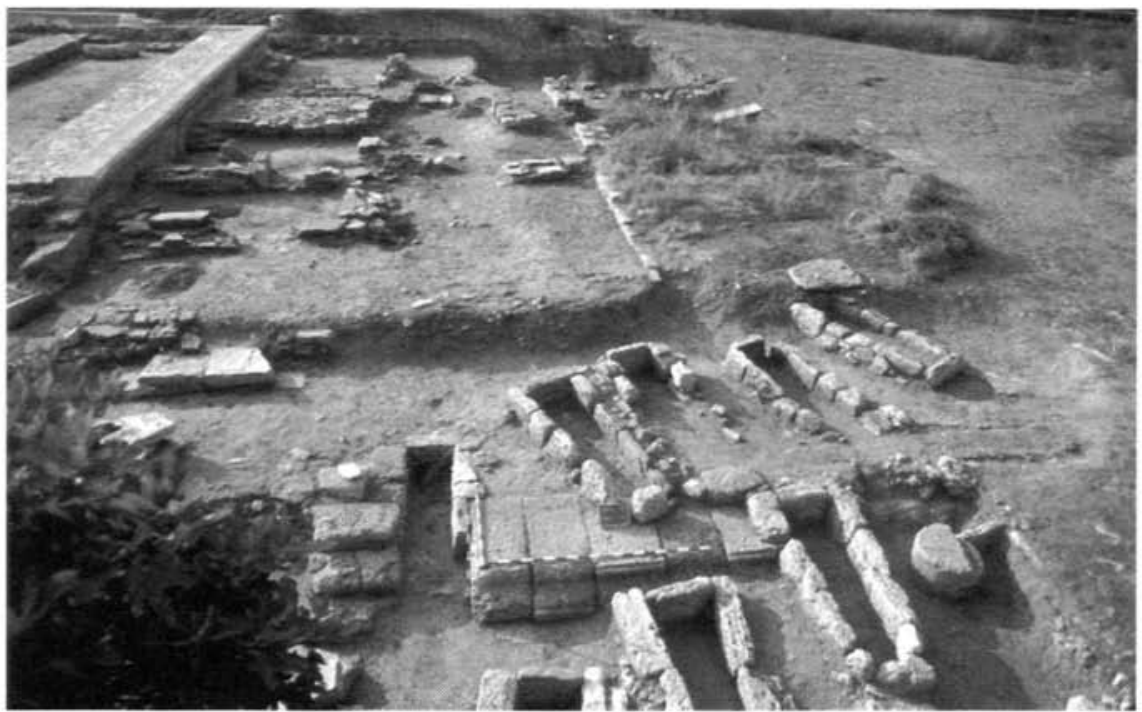

Lámina 11. Niveles tardorromanos y medievales de amortización del área del Foro. Área de necrópolis

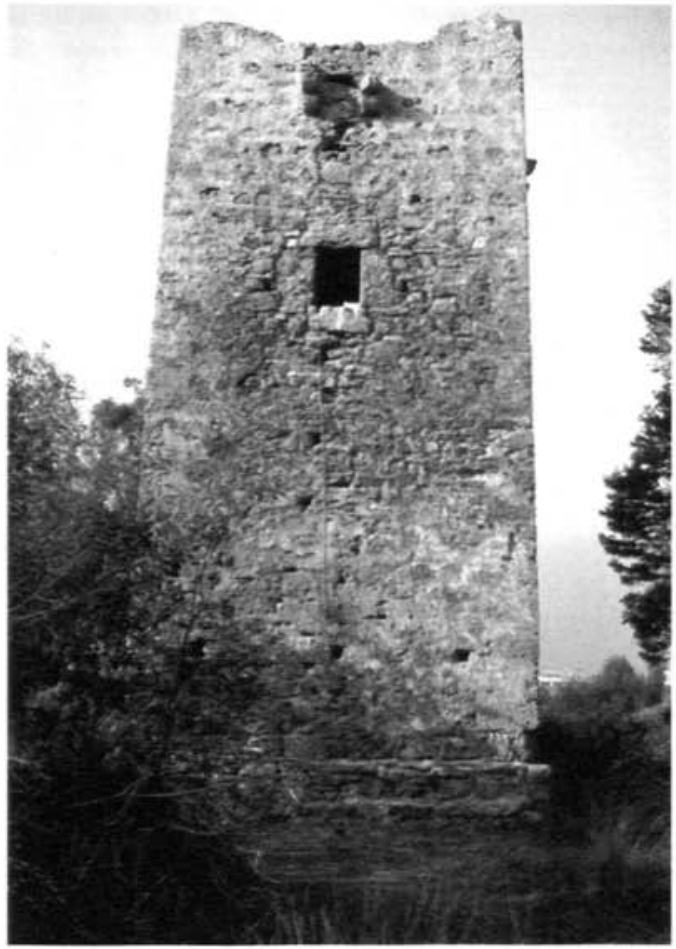

Lámina 12. Vista general de la Torre almenara, también llamada -Torre Cartagena- 


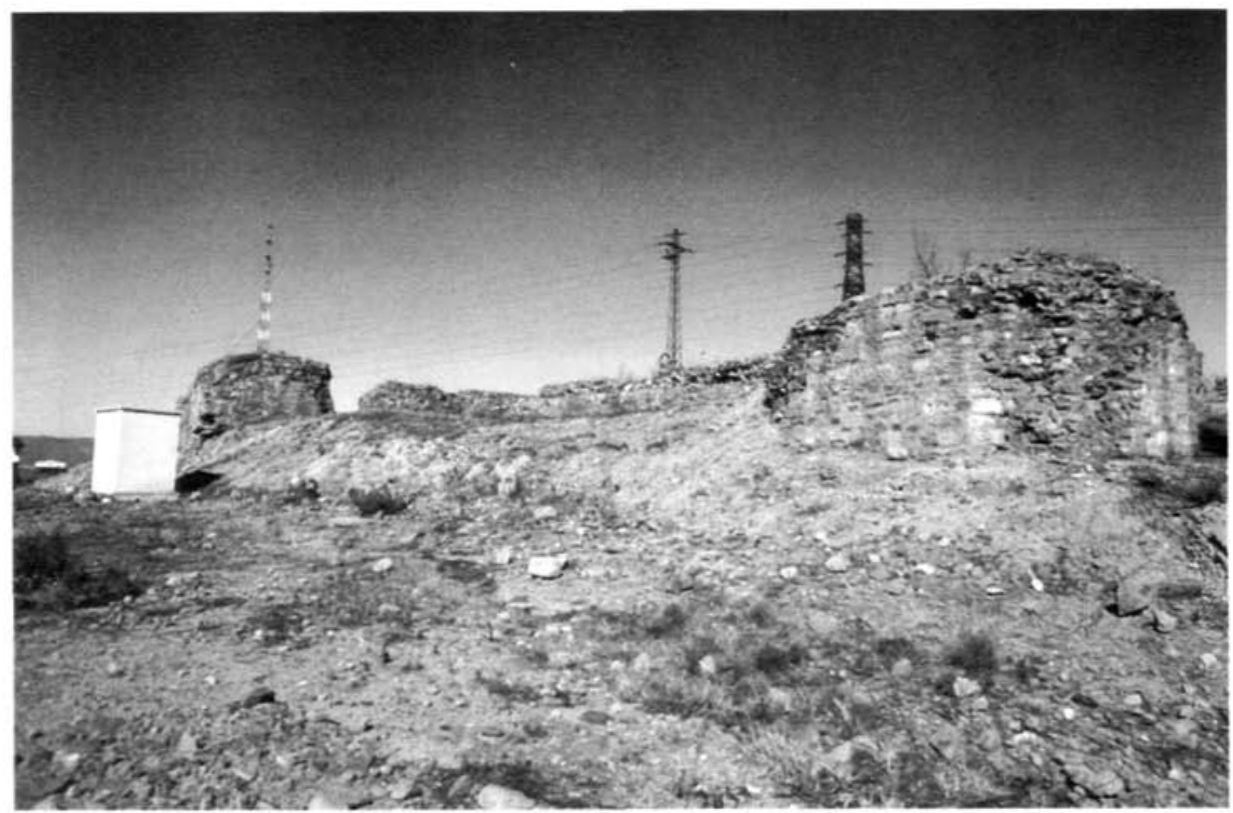

Lámina 13. Vista general del Recinto fortificado medieval

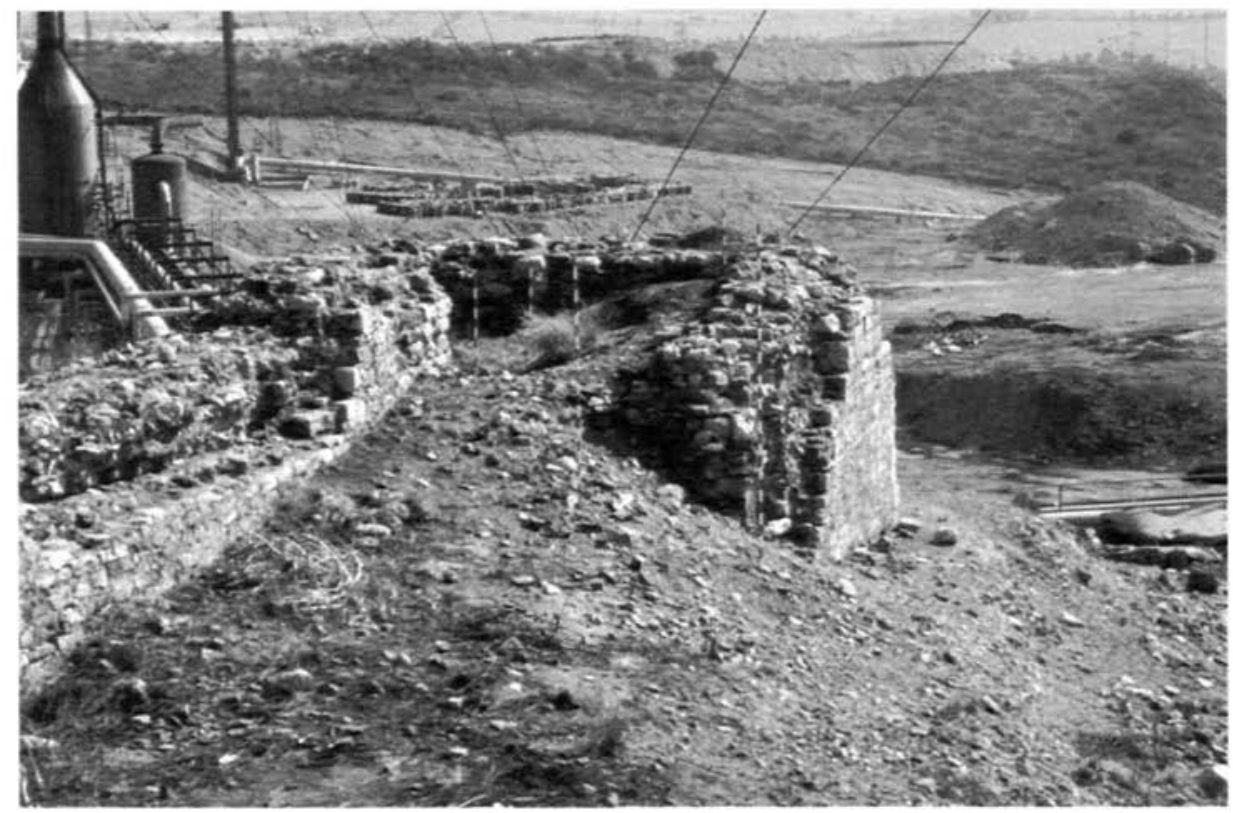

Lámina 14 Vista general del acceso en codo. Recinto fortificado medieval 